\title{
Synthesis of gold nanorods and their performance in the field of cancer cell imaging and photothermal therapy
}

\author{
Naseer Ullah Khan ${ }^{1}$, Jing Lin ${ }^{1,2}$, Muhammad Rizwan Younas ${ }^{4}, X_{\text {Xkun Liu }}^{1,3}$ and Liming Shen ${ }^{1 *}$ (D)
}

\author{
${ }^{*}$ Correspondence: \\ slm@szu.edu.cn \\ ${ }^{1}$ College of Life Science \\ and Oceanography, \\ Shenzhen University, \\ Shenzhen 518071, People's \\ Republic of China \\ Full list of author information \\ is available at the end of the \\ article
}

\begin{abstract}
Cancer is one of the most common incident in the world, with malignant tumors having a death rate of up to $19 \%$. A new method of treating cancer cells effectively with minimal cytotoxicity is needed. In the field of biomedicine with unique shapedependent optical properties, gold nanorods (GNRs) have attracted worldwide interest. These nanorods have two distinct plasmon bands. One is transverse plasmon band in the area of visible light, and the other is longitudinal band of plasmons in near infrared region. These specific characters provide promise for the design of new optically active reagents that simultaneously perform light-mediated imaging and photothermal cancer treatment. We begin our review by summarizing the latest developments in gold nanorods synthesis with a focus on seed-mediated growth method. Nanorods spontaneous self-assembly, polymer-based alignment and its applications as a novel agent for simultaneous bioimaging and photothermal cancer therapy are listed in particular.
\end{abstract}

Keywords: Bioimaging, Cancer cells, Gold nanorods, Plasmon band, Photothermal therapy

\section{Introduction}

Cancer is the second largest cause of mortality, after heart disease. Cancer has a significant impact in both physical and mental health of patient (Smith et al. 2013). Currently, cancer proteins that are abnormally generated and secreted into body fluids (blood, urine, or sweat) during a disease state are being used for early cancer detection (Rusling 2013). While doctors believe that biomarker tests alone are insufficient to accurately detect cancer, they rely on biopsies performed using ultrasonography to locate malignant areas. There is still a chance of missing, because it may not be able to identify specific areas of the cancerous tissue. Even before the existence of cancer is known, it will cause great discomfort to the patient mentally and physically. In addition to only determining the existence of cancer, staging or identifying the extent of cancer also plays an important role in determining appropriate treatment options.

Various biomedical imaging methods, such as proton magnetic resonance (MR) spectroscopy, diffusion weighted MR imaging, arterial spin labeling, computed tomography 
and MR imaging, are employed in all stages of cancer care (Razek and Castillo 2009; Razek et al. 2019; Gholizadeh et al. 2020; Razek et al. 2011). These approaches form an important part of the cancer clinical practice and can provide morphological, structural, metabolic and functional information. Integration with other diagnostic procedures (for example, in vitro tissue and bodily fluid analyses) facilitates clinical decision-making. However, some imaging techniques such as computed tomography or MR imaging are incapable of detecting small areas of malignant tissue, such as lymph nodes (Razek et al. 2019; Gollub et al. 2019; Mori et al. 2017). In certain cases, invasive biopsy are required to achieve differential diagnosis (Kim et al. 2012). Therefore, there is a compelling need for a diagnostic tool that can detect disease states with less complexity and greater confidence, which can enhance the possibility of survival of cancer patients and give better therapeutic options.

Due to advances in the field of nanotechnology, theses shortcoming has been resolved by the use of nanoparticles, such as aggregated gold nanoparticles, gold nanoshells, gold nanocages, hollow $\mathrm{Au} / \mathrm{Ag}$ dendrites, gold nanorods, carbon nanotubes, nanoclusters, nanostars, nanocubes, and copper sulfide nanoparticles (Chen et al. 2013; Han and Choi 2021; Hu et al. 2008; Khlebtsov et al. 2013; Li et al. 2010a; Lv et al. 2021; Peng et al. 2014; Perera et al. 2020; Wong et al. 2013; Zhan et al. 2019). Their application in drug delivery, cancer cell diagnostics, and therapy has long been a subject of research (Cho et al. 2021; Liu et al. 2020; Mantri and Jokerst 2020; Torres-Vanegas et al. 2021). Photothermal therapy studies has found significant drawbacks in these approaches. The formation of gold nanoshells and cages, in particular, is relatively challenging, requiring a complex gold coating procedure. The highest absorption of spherical gold nanoparticles occurs between 400 and $600 \mathrm{~nm}$. Therefore, in vivo applications have very poor light penetration and consequently inefficient photothermal heating (Huang et al. 2008). GNR, on the other hand, does not have these drawbacks. They are easily synthesized and have an adjustable aspect ratio for NIR light absorption. Even so, GNR remains clinically restricted due to cytotoxicity produced by residual cetyltrimethylammonium bromide (CTAB), which acts as a template during GNR synthesis. In order to reduce this cytotoxicity, polymers are widely used to modify the surface of GNRs by electrostatic adsorption (Leonov et al. 2009). We believe GNRs have a promising future in various applications. In terms of diagnosis, there is a growing need for point-of-care testing in both human and veterinary medicine. For years, people have predicted the doom of gold in lateral flow experiments, preferring to use alternative labels, such as latex or quantum dots, but GNRs provide a wide range of colors that make them ideal for multiplexing, which is where this technology is heading.

To date, several methods have been used to synthesize GNR through wet chemistry, including template method (Longoni et al. 2021), electrochemical method (Chapagain et al. 2021; Lu et al. 2021; Yu et al. 1997), photochemical method (Park and Song 2021), and seed-mediated growth method (Harper-Harris et al. 2021; Jana et al. 2001a,2001b; Nikoobakht and El-Sayed 2003; Peters et al. 2015; Qazi and Javaid 2016). Martin et al., first employed a templating process to produce GNR by electrochemically depositing gold in polycarbonate or alumina film pores (Martin 1996). The diameter of the nanorods produced by this method is equal to the diameter of the hole, so it was quite controllable. In the 1990s, Chang et al. (Chang et al. 1999; de Oliveira et al. 2020) proposed an 
electrochemical method to prepare GNR with high yield. In this process, the gold metal plate anode and the platinum plate cathode were immersed in an electrolytic solution with a mixed surfactant system consisting of $C T A B$ and tetradodecylammonium bromide (TDTAB). The gold ions formed by electrolysis of gold-metal anode are reduced in the cathode to gold atoms. Thus, it is possible to synthesize nanorods with longitudinal SPR up to $1050 \mathrm{~nm}$. A strong yield of rods with different aspect ratio can be achieved by adjusting the silver concentration, which results in longitudinal SPR at $600-800 \mathrm{~nm}$.

However, the seed-mediated growth method has earned the greatest attention among all methods of synthesizing GNRs due to its simple process, high yield of nanorods and easy control of the aspect ratio (Kim et al. 2019). Despite the fact that a large number of outstanding and well-cited articles on GNRs have been published, they have also been used in many other fields, such as surface enhanced Raman scattering sensing (Boyne et al. 2017), chemical imaging (Ramasamy et al. 2014), localized surface plasmon resonance sensing (Cao et al. 2014), and cancer treatment (Kwon et al. 2020). To the best of our knowledge, previous studies have not focused specifically on the use of GNRs as a new agent for simultaneous bioimaging and photothermal cancer treatment. This aspect is directly addressed in this article, which is intended to supplement the body of knowledge in this area by reviewing both key fundamental aspects and recent progress in the GNRs spontaneous self-assembly process, polymer-based alignment, and its applications in realizing simultaneous cancer cell imaging and photothermal cancer therapy. We will also focus on an overview of the GNR preparation process via seed-mediated methods and their growth mechanism.

\section{Progress in the synthesis of gold nanorods}

In order to more thoroughly investigate the properties of gold nanorods, researchers have developed many effective methods for preparing gold nanorods, including hard template method, photochemical method, electrochemical method, seed-mediated growth method, secondary growth method, and amorphous seed method. Seed-mediated growth is the most commonly used method for producing monodisperse metal nanoparticles.

\section{Seed-mediated method and its growth mechanism}

\section{Seed-mediated method}

The seed-mediated growth method can be traced back to 1989. A study reported a method of preparing equidistant gold colloids by reducing auric acid $\left(\mathrm{HAuCl}_{4}\right)$ in the presence of small colloidal gold nuclei (Ortiz-Castillo et al. 2020; Wiesner and Wokaun 1989). To form gold nuclei, white phosphorus was added to the $\mathrm{HAuCl}_{4}$ solution, and $\mathrm{H}_{2} \mathrm{O}_{2}$ was added to initiate the growth of GNR. Another study pioneered the current concept of seed-mediated growth method by incorporating citrate-capped small gold nanospheres into a bulk $\mathrm{HAuCl}_{2}$ growth solution produced by reducing $\mathrm{HAuCl}_{4}$ with ascorbic acid in the presence of surfactant CTAB and silver ions (Jana et al. 2001b). In the presence of metal nanoparticles that catalyze the reduction reaction, ascorbic acid may only reduce gold ions to gold atoms. In the absence of silver nitrate, the same team expanded and strengthened the process via a three-step process such that the long rods' length-to-diameter ratio does not exceed 25 (Gao et al. 2021). Gold nanorods are used as 
seeds for the second growth and subsequently as seeds for the third growth in a standard procedure (Murphy et al. 2005). The disadvantage of this technique is that it creates a large portion of gold nanospheres, requiring a time-consuming centrifugation process to separate the rod from the spheres. It was also found that the addition of nitric acid to the third growth medium of seeds helped to form gold nanorods with a high aspect ratio and increased monodispersity and yield (Roy et al. 2020; Wu et al. 2005).

Two modifications were made to this system: a stronger CTAB stabilizer was used instead of sodium citrate in the seed forming process, and silver ions were used to regulate the aspect ratio of gold nanorods (Nikoobakht and El-Sayed 2003). The scheme consists of two steps: (i) synthesis of seed solution in the presence of ice-cold sodium borohydride by reducing auric acid in the presence of CTAB and (ii) the addition of seed solution in the presence of $\mathrm{CTAB}$ in the presence of $\mathrm{Au}^{+}$stock solution. It is obtained by ascorbic acid reduction of $\mathrm{HAuCl}_{4}$. In order to facilitate rod formation and change in aspect ratio, silver nitrate was added into the gold solution prior to adding the seed crystals. With an aspect ratio of 1.5 to 4.5 , this method can produce high-yield gold nanorods (99\%) and prevents repeated centrifugal separation of spheres. Overgrowth can be prevented by fast centrifugation or by adding sodiumsulphide (Zweifel and Wei 2005).

The co-surfactant benzyl dimethyl hexadecyl ammonium chloride (BDAC) has been added into the original growth solution to grow nanorods with a higher aspect ratio. This binary surfactant system can generate nanorods with an aspect ratio of up to 10 by adjusting the concentration of silver (Nikoobakht and El-Sayed 2003). Using the Pluronic F-127 co-surfactant system, the aspect ratio can be increased to 20 with acceptable monodispersity (Iqbal et al. 2007). In order to grow nanorods with the desired aspect ratio, at a rate of $1.0 \mathrm{~mL} / 20 \mathrm{~min}$ after the first stage of nanorod growth, the gold growth solution can be gradually applied to nanorods solution to induce continuous growth of the rods (Nikoobakht and El-Sayed 2003). By incorporating the growth medium with increased volume for the fourth time, the aspect ratio is as high as 70 with the shape shift from spindle to one-dimensional rods (Chen et al. 2005). Many parameters, such as seed concentration, size, structure, ascorbic acid concentration, temperature, $\mathrm{pH}$, gold precursor concentration, surface active agent concentration, using other surfactants, additives, solvents, and even the ageing time of nanorods, all affect the yield, monodispersity, size and fine shape of gold nanorods in these two method (Iqbal et al. 2007; Meng et al. 2020; Murphy et al. 2005; Zweifel and Wei 2005).

In order to obtain nanostructures of different shapes, gold nanorods themselves can be used as seeds (Ban et al. 2014; Wang et al. 2005a,2014). Furthermore, CTAB surfactant impurities play a significant role in growth of nanorods. CTAB from various manufacturers and various catalogue numbers not only affects the aspect ratio of nanorods due to the presence of impurities, but also affects the yield and monodispersity (Smith and Korgel 2008). A main shape-directing component was found to be iodide contaminants, because they selectively bind to $\mathrm{Au}(111)$ facets that induce the formation of gold nanorods (Millstone et al. 2008). 


\section{Growth mechanism}

In synthesizing GNRs with seed-mediated method, there are two stages: the synthesis of the gold nanoparticles (GNPs) seeds is the first step, and the development of these seeds into nanorods is the second step. First, single crystalline seed GNPs of less than $4 \mathrm{~nm}$ are prepared in an aqueous CTAB solution by decreasing $\mathrm{HAuCl}_{4}$ with ice cold sodium borohydride $\left(\mathrm{NaBH}_{4}\right)$. Second, the growth solution is prepared by adding ascorbic acid to an aqueous solution of $\mathrm{HAuCl}_{4} \mathrm{CTAB}$ and silver nitrate $\left(\mathrm{AgNO}_{3}\right)$ as a mild reducing agent with the purpose of reducing $\mathrm{Au}^{3+}$ to $\mathrm{Au}^{+}$. When the seed solution is applied to growth solution, GNPs seeds are able to catalyze existing ascorbic acid on their surface by decreasing the $\mathrm{Au}^{+}$to $\mathrm{Au}^{0}$. This enables addition of gold atoms to surface of the seed's nanoparticles, thereby forming nanorods. The CTAB's function is that of surfactant-templating shape. Numerous theories exist about the CTAB templating process in rod formation. In one of them, CTAB is thought to be preferentially bound to (110) or (100) gold faces and leaves the (111) face for the addition of gold atoms, resulting in the growth of nanorods along the (100) face (Canizal et al. 2001; Shilpi and Khatri 2015). In the second mechanism, gold dichloride $\left(\mathrm{AuCl}_{2}\right)$ binds to $\mathrm{CTAB}$ to form the $\mathrm{AuCl}_{2}$-CTAB complex after ascorbic acid reduction of $\mathrm{HAuCl}_{4}$ in the growth solution. This complex binds at a faster rate to the tip of seed GNPs than side faces, leading to growth of nanorods (Kim et al. 2006b). As silver nitrate $\left(\mathrm{AgNO}_{3}\right)$ is applied to the CTAB solution, results in the immediate formation of silver bromide (AgBr). It has been claimed that in the form of $\mathrm{AgBr}, \mathrm{Ag}^{+}$ions adsorb onto the surfaces of GNPs, and $\mathrm{Ag}^{+}$ is reduced at a faster rate to Ag atoms on the side (110) face of the nanorods than on the (111) end face. This prevents the addition of gold to the side faces and thus results in the creation of nanorods. By either changing the volume of seed solution or the quantity of $\mathrm{AgNO}_{3}$ applied to growth solution, the aspect ratio of GNRs can easily be tuned.

\section{Electrochemical method}

High yields of gold nanorods were primarily prepared by electrochemical method in 1990s, prior to the advent of seed-mediated growth method (Yu et al. 1997). By extending their electrochemical methods to synthesize metal clusters in reverse micelles, they documented the process of forming gold nanorods. In this process, gold metal plate anode and the platinum plate cathode are immersed in an electrolyte composed of rodinduced dodecyl ammonium bromide (TOAB) CTAB surfactant and co-surfactant. The effect of electrolysis is the generation of gold ions from gold metal anode in the form of Tetrabromoaurate $\left(\mathrm{AuBr}_{4}\right)$, which are then complexed with CTAB micelles and migrated to cathode, where the gold ions are reduced to gold atoms. In order to monitor the aspect ratio of nanorods through concentration and release rate of silver ions produced by the redox reaction between gold ions and silver plate, the silver plate is gradually inserted into the solution. Acetone and cyclohexane are added prior to electrolysis to facilitate the mixing of CTAB and TOAB and help form rod-shaped CTAB micelles, respectively. Dissipating the rod from cathode requires ultrasonic therapy. On the longitudinal surface of GNRs, CTAB forms a double-layer structure, and the first-layer trimethylammonium head group faces the gold surface (Li et al. 2020b). 


\section{Other methods}

Another common synthesis method is photochemical reduction, which is the earliest method used to form colloidal gold nanorods (Aazam and Zaheer 2020). In this process, auric acid combines with rod-shaped cationic micellar surfactants to form pairs of ions, then the electrons are transferred from metal ion to ligand by ultraviolet excitation to reduce the metal ion to form a metal (Marangoni et al. 2016). Because of the unique crystal plane stabilization effect of surfactant micelles, metal cores aggregate to form primary particles and primary crystals aggregate to form rod-like structures. It has been suggested that the formation of rods is due to a two-step aggregation process. By changing the size of micelles and process of particle crystallization (Leontidis et al. 2002), the addition of sodium chloride electrolyte increases the percentage and length of nanorods. The presence of silver ions substantially increases nanorode yield and uniformity, which is due to the seed-mediated growth method (Kim et al. 2002). Compared with $254 \mathrm{~nm}$ light, $300 \mathrm{~nm}$ ultraviolet light leads to longer nanorods with a narrower size distribution, and increasing light intensity accelerates the growth of gold nanorods (Miranda and Ahmadi 2005).

The high yield and monodispersity of gold nanorods can also be developed by a onestep seedless method, where sodium borate is directly added to growth solution in the presence of silver ions, ascorbic acid and CTAB surfactant to initiate particle nucleation and growth. It is possible to monitor the aspect ratio of nanorods by changing the amount of sodium borate or by modifying the temperature (Jana 2005; Zijlstra et al. 2006). Biological reduction, X-ray irradiation, proton beam irradiation, microwave reduction and solvothermal reduction (Canizal et al. 2001; Cao et al. 2005; Kim et al. 2006b; Shilpi and Khatri 2015; Zhu and $\mathrm{Hu} 2003$ ) are other preparation methods. Although these techniques are not so common, but provide a good complement to the development of colloidal gold nanorods. The template method is also a popular method for the preparation of aligned nanocomposites of the necessary materials and can also be used for preparation of colloidal gold nanorods by separating nanoparticles from the substrate and then dispersing them in a solvent (Wongkaew et al. 2019). The benefit of this approach is that molecules are not covered by the prepared nanorods, so that the chemical treatment of surface is simple and the length, width and uniformity of nanorods can be regulated precisely by solid template.

\section{Surface functionalization of gold nanorods}

The study of surface functionalization of gold nanorods has made considerable progress in recent years. For instance, it has been shown that the most effective way to improve its biocompatibility is to coat organic or inorganic materials on gold nanorods and to substitute CTAB with sulfhydryl-terminated molecules.

Silicon dioxide $\left(\mathrm{SiO}_{2}\right)$ or a polymer are typically used for the surface coating process to directly coat the surface of gold nanorods. The $\mathrm{SiO}_{2}$ coated gold nanorods can not only minimize toxicity but also avoid their aggregation because of the efficacy and high hardness of $\mathrm{SiO}_{2}$ coating. Furthermore, the $\mathrm{SiO}_{2}$ coating creates pores, and can also be used for drug delivery (Luo et al. 2016). The low-cost biological macromolecule bovine serum albumin (BSA) is commonly used in biomedicine. BSA has also been used to coat 
the surface of gold nanorods in order to enhance the biocompatibility of gold nanorods. Gold nanorods are quickly coated by BSA when mix together due to effective thiol binding sites on BSA. If BSA is coated by extinction spectroscopy on gold nanorods, it is simple to confirm, and the overall absorption of gold nanorods indicates an obvious red change after covering BSA. It has been shown that small BSA-coated gold nanorods demonstrate enhanced biocompatibility (Ali et al. 2014).

Reduction of saturated silver chloride aqueous solution by hydroxylamine oxide can also chemically deposit silver shells on gold nanorods (Sethi et al. 2019). By changing the silver precursor and mild reduction agent concentration (Zhang et al. 2015), the silver thickness can be controlled. Silver coating can be dissolved selectively by hydrochloric acid in order to recover the gold nanorods. A few nanometer coatings of nanorods can result from clearer, stronger and blue-shifted surface plasmon absorption bands (Becker et al. 2008). Gold/silver core/shell nanorods have an extended storage time due to decomposition of the silver shell into silver nanoparticles, so the period of stability as long as several months, which constitutes the drawback of nanocomposites (Liu and Guyot-Sionnest 2004). The technique of ligand exchange to extract CTAB on the surface of gold nanorods is another widely used process. Because of the strong $\mathrm{Au}-\mathrm{S}$ covalent bond, sulfhydryl-terminated molecules, such as 11-mercaptoundecanoic acid and thiol-terminated polyethylene glycol (SH-PEG), are used for this process instead of CTAB. Several studies have shown that 11-mercaptoundecanoic acid can effectively replace CTAB in GNRs (Song et al. 2015; Wijaya and Hamad-Schifferli 2008; Yu et al. 2007). The 11-mercaptoundecanoic acid thiol group may be tightly bound to GNRs by $\mathrm{Au}-\mathrm{S}$ bond, and the 11-mercaptoundecanoic acid carboxyl group may be combined with other biological molecules which are useful in biomedical fields for the application of GNRs. However, their widespread use in biological nanorods is limited by the low content of 11-mercaptoundecanoic acid-terminated GNRs In the surface modification of GNRs, thiol-terminated polyethylene glycol (SH-PEG) with functional group (-NH2 or - $\mathrm{COOH}$ ) has been commonly used, since PEG can escape unwanted protein adhesion, is non-toxic and has strong water solubility (Boyer et al. 2010). The CTAB can be fully removed, as shown in Fig. 1, once the SH-PEG is added through ligand exchange to CTAB-capped gold nanorode solution. Numerous studies have shown that PEG-coated gold nanorods can effectively improve biocompatibility and have been used for imaging and photothermal therapy.

Other hard coatings include iron oxide coating by coprecipitation of iron salts or electrostatic adsorption of nanoparticles of iron oxide (Chapman et al. 2017), platinum coating by mild reduction of ascorbic acid platinum salts (MB et al. 2020), and silver sulphide or selenide coating by exposure to sulphide or selenide salts in an oxidizing setting by golg/silver core/shell nanorods (Liu and Guyot-Sionnest 2006). These coatings are promising in the applications of magnetic separation and imaging, catalysis, and optical nonlinearities, respectively.

Direct ligand exchange, covalent coupling, electrostatic adsorption, and surface coating are the four methods for conjugating biomolecules to GNRs that have been developed. Thiolated biomolecules, such as PEG and DNA, bind tightly to GNRs by Au-S bonds in direct ligand exchange. Small bifunctional molecules, such as 11-mercaptoundecanoic acids, are used as a linker to add functional carboxyl groups for further 


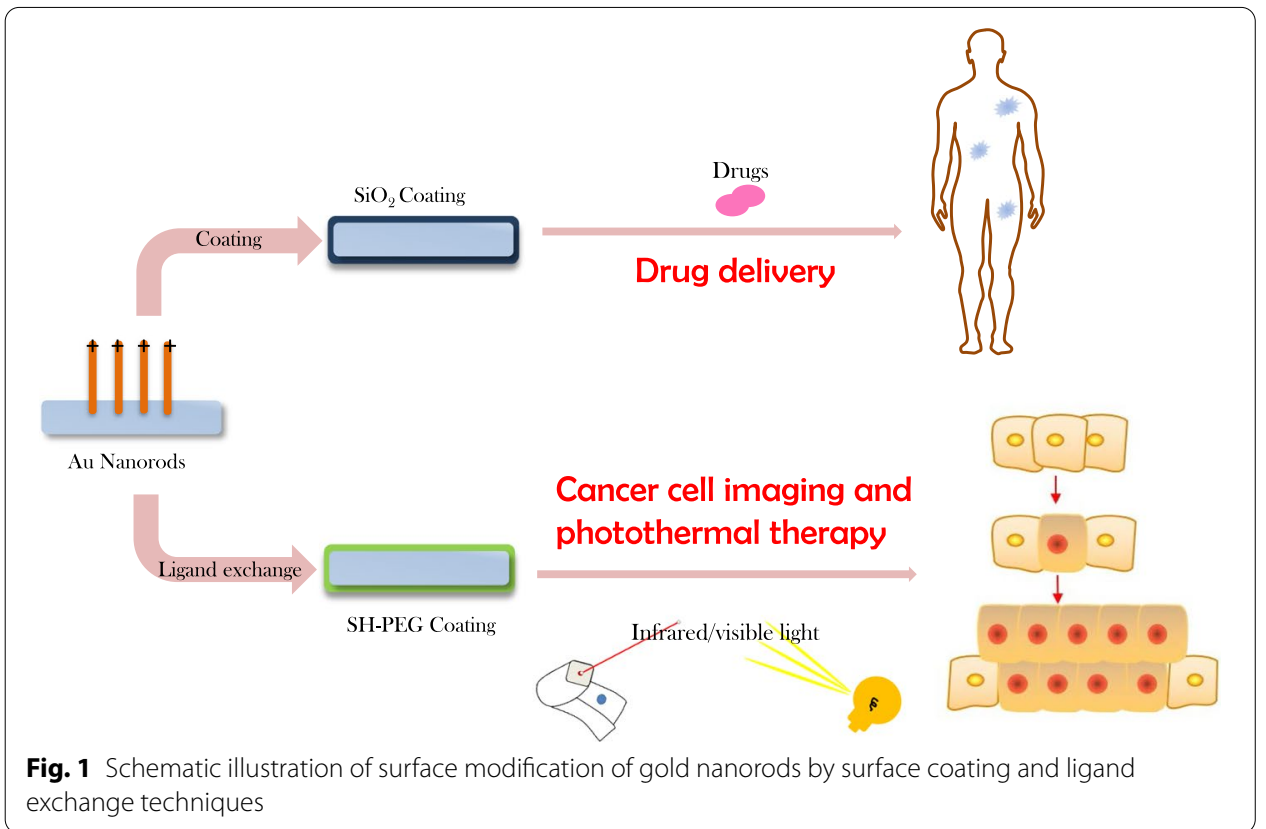

bioconjugation with antibody and protein using a carbodiimide binding agent in covalent coupling (Du et al. 2019; Truong et al. 2011; Wang et al. 2012). Electrostatic activity allows charged proteins, such as antibodies, to adsorb on GNRs. Since the protein is negatively charged at $\mathrm{pH}$ levels greater than its isoelectric point, it can be directly adsorbed to GNRs by electrostatic attraction (Pissuwan et al. 2007). This approach is the simplest; however, its long-term stability must alterialso be discussed. Surface coating begins with the use of polymeric compounds to layer GNRs and then the biomolecules react with polymer by electrostatic adsorption or hydrophobic interactions (Huang et al. 2008). Although electrostatic adsorption and surface coating are simpler and quicker than direct ligand exchange and covalent coupling procedures that entail ligand exchange, but the long-term storage stability of electrostatic adsorption is uncertain, particularly when used in vivo..

\section{Radiative and non-radiative properties of GNRs}

\section{Radiative properties}

In the case of gold nanorods, electrical vibrations can occur in one of two directions depending on the polarization of the incident light: the short axis and the long axis. In the visible light field, the excitation of surface plasmon oscillation along the short axis causes an absorption band. The absorption band's wavelength is identical to the gold nanospheres wavelength, which is called the transverse band. In the longer wavelength field, called the longitudinal band, the excitation of surface plasmon oscillation along the long axis induces a stronger absorption band. The longitudinal band has a red change from the visible region to the near-infrared region, while the lateral band is not sensitive to size of the nanorods, as the aspect ratio (length/width) increases. According to the Gans theory, which was built based on the dipole approximation to describe the optical 
properties of ellipsoidal particles, this optical behavior can be well understood (Thirkill 2000).

Not only do the absorption, dispersion and total extinction of gold nanorods depend on the wavelength of light, but also the aspect ratio and particle size. To theoretically research the relative effect of absorption and scattering on total extinction, Lee and ElSayed used Discrete Dipole Approximation, which is a powerful tool for calculating optical properties (Fan et al. 2021; Lee and El-Sayed 2005; Parviainen and Lumme 2008). Their analysis found that the scattering quantum yield increased from 0.326 for spherical to 0.603 only by expanding the shape. This may be due to the change of plasmon process in nanorods relative to nanospheres, which is substantially reduced. The absorption efficiency of the smaller rods dominates at a fixed aspect ratio, and the scattering efficiency of the bigger rods dominates (Lee and El-Sayed 2005). For gold nanospheres, a related phenomenon often applies (Jain et al. 2006). For biomedical applications, these studies provide the gold standard for selecting gold nanoparticles. Larger nanoparticles are preferred for imaging, because they have greater scattering ability, whereas smaller nanoparticles are preferred for photothermal therapy, because light is primarily absorbed by the particles and thus effectively converted to heat for the destruction of cells and tissues. It has been observed that the quantum efficiency of photoluminescence (PL) for nanorods with an aspect ratio of less than 3 is in the range of $10^{-4}$ to $10^{-3}$, which is 6 orders of magnitude greater than the quantum efficiency found in bulk (Craciun et al. 2021). In addition, with increasing aspect ratio, it is found that the maximum value of the PL wavelength increases linearly. At the same time, the quantum efficiency will squarely increase and then begin to decrease when the aspect ratio is less than 3. A detailed analysis of the increased emission strength of nanorods, including high aspect ratios, was performed in a previous study (Eustis and El-Sayed 2005). Studies have shown that the severity of the enhanced emission will decrease as the aspect ratio rises above 3.5. The author uses simulations to show that the emission depends on: (i) the intensity of plasmon field in the longitudinal band; (ii) this field increases absorption of light between the bands, depending on the degree of overlap between the bands, the absorption band and the absorption of SPR; and (iii) the plasmon field increases the outward fluorescence emission, depending on the overlap. The SPR absorption changes to longer wavelengths as the aspect ratio of the nanorods increases, so the degree of overlap between the interband phase and the SPR absorption band will continue to change. Initially, increasing the aspect ratio would lead to greater overlap, which will lead to increased emission. At some point, however, a further increase would decrease the degree of overlap, resulting in lower emissions.

\section{Non-radiative properties}

In order to study the conversion of absorbed light into heat via a series of photophysical processes, ultrafast kinetics has been used (Yaseen et al. 2021). Basically, the rapid loss of phase of coherently excited electrons on a time scale of a few femtoseconds (fs) starts with these photophysical processes. The second is the depletion of the phononbath's energy. Via the electron-phonon method, the electrons and holes decrease the energy level by around $0.5-1$ picosecond (ps). The mechanism of relaxation is independent of size and shape, and also the horizontal or vertical plasmons in the rod (Lien et al. 2020). 
The lack of participation of surface phonons in hot electron relaxation is clearly supported by this. By transferring its heat to the surrounding medium by phonon-phonon relaxation within approximately $100 \mathrm{ps}$, the lattice is cooled. The final process results in complete cooling of the entire nanoparticle.

The coherent vibration mode can be pulsed in the process of rapidly heating the particle lattice after laser excitation, resulting in transient oscillation of the absorption signal. This is because the volume of the particles' crystal lattice regularly varies as the laser heats the particles. As a consequence, the electron density decreases and increases over the same period, resulting in the SPR wavelength's maximum red shift and blue shift relative to the lattice's equilibrium position. The coherent vibrational motion of gold nanospheres and nanorods was studied by Hartland and colleagues (Hartland 2006). The nanospheres vibration period is around $5 \mathrm{ps}$, and the period is inversely proportional to the radius of particles. The nanorod vibration time is around $50 \mathrm{ps}$, which varies with the length of rod linearly. It also depends on the probe wavelength, because the sample width is not uniform. The phase changes by $180^{\circ}$ when observed on the red and blue sides of the longitudinal surface plasmon zone. The plasmon and lattice motion coupling was also observed by Huang et al. The coherent motion of nanodisk pairs on lithographic samples has been studied (Huang et al. 2007a).

Link et al. discovered that by using a high-energy 7-ns laser or a higher energy 100-fs laser, nanorods melted into near spherical particles of comparable volumes at moderate energies using a 100-fs laser at $800 \mathrm{~nm}$ (Khanal and Zubarev 2019). The energy threshold of single rod melting laser is estimated to be approximately $60 \mathrm{fJ}$, and energy threshold of the nanosecond laser is increased by 100 times due to the low efficiency and slow heating process (Link and El-Sayed 2001). To measure the bleaching rate of longitudinal surface plasmon absorption after the nanorods were melted into spheres, the pump probe fs transient absorption spectroscopy was used to measure the bleaching rate of longitudinal surface plasmon absorption after the nanorods were melted into spheres, and found that it takes around 35 ps to turn the nanorods into spheres (Link et al. 1999b). They find that this photothermal melting starts with the creation of defects within the nanorods using high-resolution TEM, followed by surface diffusion and reconstruction, which is distinct from surface thermal melting (Link et al. 2000).

Unlike laser photothermal reshaping, the reshaping of gold nanorods with micelles by dissolving the micelles with heat was stated by Mohamed et al. (Della Picca et al. 2018; Mohamed et al. 1998). Since the dissolution temperature of long micelles is lower than that of short micelles, the average length of remaining rods in the solution will be decreased by precipitation of long rods and the overall absorption peak will change to blue. This offers an easy way to reshape the distribution of gold nanorods in terms of scale.

\section{Self-assembly of GNRs}

The spontaneous self-assembly of colloidal nanoparticles depends on the particle shape, size distribution and capping molecules. Although spherical nanoparticles require a narrow distribution of size, with a certain degree of polydispersity, anisotropic nanoparticles can self-assemble into different modes (Sumer and Striolo 2020). The self-assembling of gold nanorods was first recorded by Nikoobakht et al. They found large and aligned gold 
nanorods structures on the copper TEM grid after they air-dried a drop of nanorods solution onto the grid or dried the rod solution with the grid half immersed. In particular, array is formed near the zone where the solution and grid intersect. They highlighted that the assembly is caused by an increase in lateral capillary forces between the particles as a result of water evaporation during the drying process. It is suggested that higher and later capillary forces along the length of assembled nanorods rather than the width create parallel arrangement. Concentration of surfactants, ionic strength, concentration of particles, distribution of particle size and the presence of spherical particles all affect the component's consistency and final shape. Another study found that the nanorods appear to pack together and thus detach from the spherical particles when a drop of rodball mixed solution slowly dries on the silicon wafer in a steam atmosphere to slow the sample's drying rate (Xu et al. 2006). This self-selection behavior is also explained based on the capillary force between particles and the significant shape dependence of selfassembly process.

It has been reported that surfactant concentration plays a critical role in the assembly of nanorods (Kawamura et al. 2007). The nanorods are organized linearly and loosely in a head-to-tail way if the prepared solution is centrifuged twice, and a closely organized two-dimensional parallel assembly of the nanorods is observed after three rounds of centrifugation. It has also been demonstrated that the linear head-to-tail component has a substantial surface-enhanced Raman signal, but the parallel component has no enhancement. This is because the nanorod's end component has a higher electrical field compared to the particle's side.

Jana et al. later used the polarizing microscope to observe the spontaneous forming side-by-side of a liquid crystal structure consisting of aligned gold nanorods in a high aspect ratio concentrated solution (Jana et al. 2002). The main factor was found to be the CTAB surfactant, as only the correct concentration of the surfactant will contribute to the crystal structure. The discharge of the charged head group and counter ion of the outer layer of the surfactant can cause the hydrophobic tail of the surfactant to face the solvent as a process of two nanorods. As a result, the two nanorods are attracted together in a lateral way due to the hydrophobic interaction while minimizing the hydrophobic-hydrophilic water interaction. These superstructures are thermodynamically stable, according to Onsager's theory, because the gain of translational entropy is greater than the loss of directional entropy caused by particle arrangement (Großmann et al. 2020; Onsager 1949). Because of the component's dependence on particle anisotropy and polydispersity, mixtures with different aspect ratios, spherical and other nanorods shapes were able to use the component for shape and size separation (Jana 2003). This is because liquid crystals will precipitate from the solution as the assembly consistency improves. It is easier to settle long rods than short rods, accompanied by platelet particles, which can separate particles of various shapes gradually.

It has been demonstrated that superlattices of self-assembled vertically aligned gold nanorods (VA-GNRs) can serve as probes or substrates for the detection of different molecules with ultra-high sensitivity. Sensitivity to bovine serum albumin and D-glucose solutions and the potential extension to actual samples were seen in their experiment on mixed samples of bovine serum albumin and D-glucose solutions. By depositing a drop of solvent containing the GNRs and subsequent solvent evaporation in ambient 
conditions, self-assembled superlattices of VA-GNRs were obtained on a silicone wafer. An additional benefit of the monolayers of VA-GNR is their extremely high reproducible morphology accompanied by ultra-high sensitivity that will be useful in many fields, where there is a very small amount of analyte available (Apte et al. 2015).

\section{Biological applications of GNRs}

GNRs have become a new type of nanostructure due to their excellent radiative and nonradiative properties that can be used in a variety of biological and biomedical applications, including biosensing, biomedical imaging, gene and drug delivery, disease detection, diagnosis and treatment. It is necessary to understand their potential risks to human health and the environment for possible clinical trials. In vitro toxicity studies of gold nanoparticles of various sizes, shapes and surfactants have shown that while free CTAB molecules are harmful to human cells, CTAB bound molecules are non-toxic (Auguste et al. 2021; Connor et al. 2005). Because free CTAB molecules can be separated by centrifugation or dialysis membranes, both in vivo and clinical studies of gold nanorods are very safe to use.

\section{GNRs as a cancer cell fluorescence sensing agent}

For cancer cell diagnosis and treatment, molecular recognition on complex cell surfaces plays a key role. The affinity tags that are responsible for cancer cell molecular recognition, such as aptamers and antibodies, may often have poor binding strengths on cancer cells against their molecular target, often known as a biomarker. This will decrease the affinity of signaling and binding towards certain targets. Therefore, multiple aptamers can be conjugated on a scaffold nanoparticle instead of using single aptamers for molecular recognition to produce a multivalent binding base, which can boost the signaling and increase the binding probability. GNRs are good candidate scaffolds for conjugating multiple aptamers, since they can be used as photothermal therapeutic agents after cancer cell detection. As previously shown that the fluorescence intensity coming from the cell surface is increased by more than 300 times compared to those obtained from individual aptamers according to flow cytometric measurements by using the fluorescein-labeled multiple aptamers conjugated to GNRs (Elbassal et al. 2017). The KK1HO8 aptamer that has a poor binding affinity $(\mathrm{Kd} \sim 296 \pm 41 \mathrm{nM})$ towards K-562 cancer cells was selected in his fluorescence signal amplification assay. Multiple aptamer-conjugated GNRs may also be a treatment for cases of cancer cells that have low biomarker expression levels on the cell membrane as binding sites or have aptamers with poor binding affinities against their cell membrane binding sites.

\section{GNRs as a cancer imaging agent}

Recently, multimodal imaging technology has been introduced to more reliably predict and diagnose diseases, such as cancer. If highly visible marker molecules or functional nanomaterials are produced for precise cell imaging of diseases, the imaging results can be further improved. So far, some organic fluorophores have been used for this purpose, but their use has been restricted due to limitations such as light instability caused by heavy radiation and metal quenching effects. Although several studies have shown that 
quantum dots can inhibit cytotoxicity, they can still cause long-term toxicity in vitro and in vivo (Derfus et al. 2004; Jeevanandam et al. 2021; Prasad et al. 2010).

GNR has some significant advantages over organic fluorophores and quantum dots, such as no photobleaching or decomposition cases, enhanced dispersion signal, and customizable longitudinal plasmon absorption, which are necessary for reliable contrast agents (Yang and Cui 2008). GNRs can be monitored for cancer imaging by using several imaging tools, such as dark-field mode microscopy, electron microscopy, Raman spectroscopy, two-photon enhanced luminescence (TPL), optical coherence tomography (OCT), photoacoustic tomography (PAT), ultrasound, and X-ray CT (Bai et al. 2020; Chen et al. 2010b; Ding et al. 2007; Eghtedari et al. 2007; Fernando et al. 2020; Huang et al. 2007b; von Maltzahn et al. 2009; Oldenburg et al. 2009; Villar-Alvarez et al. 2018; Wang et al. 2005b). In order to clearly image and differentiate malignant cells from nonmalignant cells with a dark-field microscope, Huang et al. used monoclonal antiepidermal growth factor receptor (anti-EGFR) conjugated GNRs in detail (Huang et al. 2007b). Because EGFR is known to be overexpressed in many malignant epithelial tumor cells, the red light on its surface from the anti-EGFR conjugated GNR is strongly distributed, so that cancer cells can be monitored brightly (Fig. 2a). Dark-field microscopy and electron microscopy were used to study the absorption and distribution by HeLa cells of transferrin (Tf)-coupled GNRs (Fig. 2b) (Ding et al. 2007). In addition, due to their highly efficient single-photon and two-photon mediated luminescence, GNRs are used as photoluminescent agents, which help them to preserve their capacity for resonate surface plasmons. GNR's TPL imaging can be imaged under confocal conditions with sub-micron spatial resolution. The TPL intensity of GNRs was found to be much stronger than that of rhodamine molecules, and the movement of GNRs in the body through blood vessels of the mouse ears was monitored (Fig. 2c) (Wang et al. 2005b). It

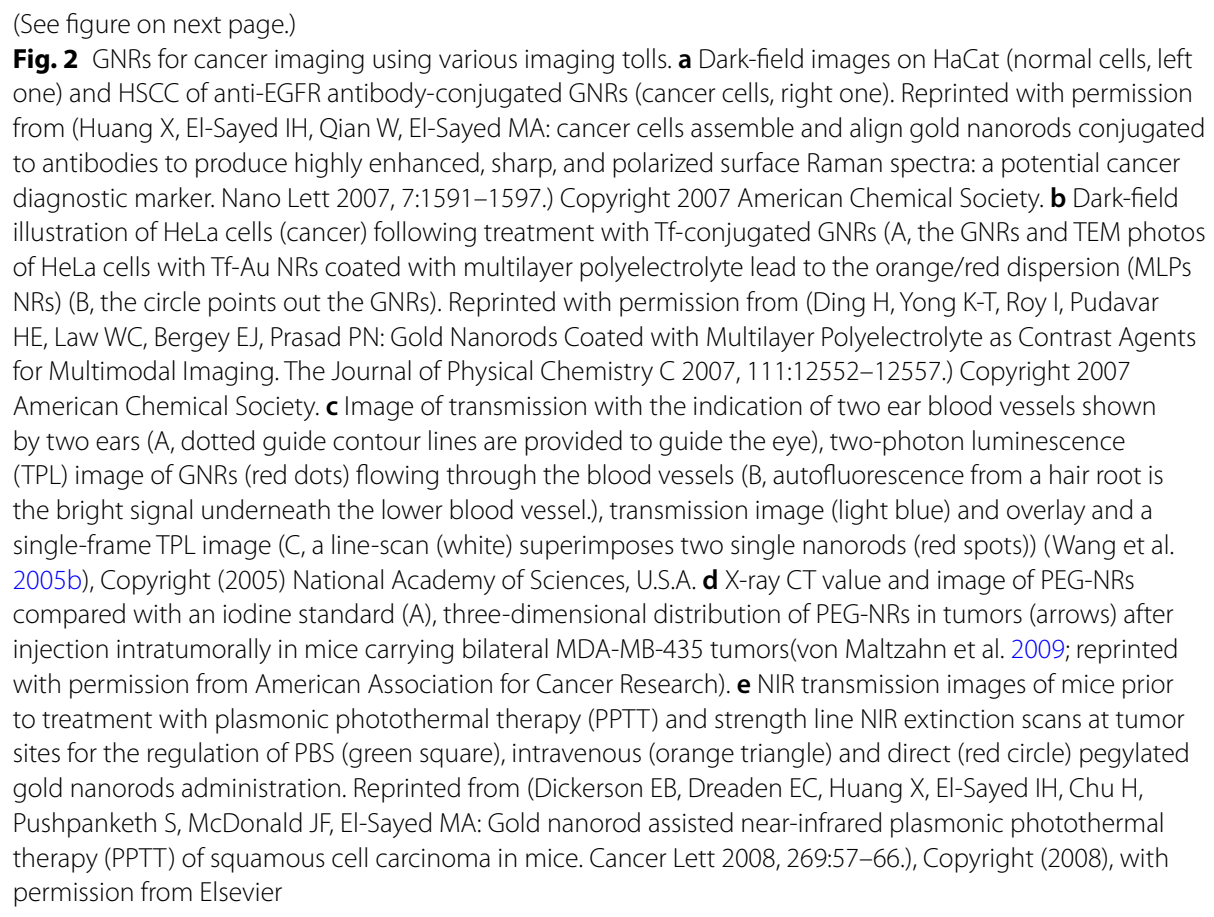
one) and HSCC of anti-EGFR antibody-conjugated GNRs (cancer cells, right one). Reprinted with permission from (Huang X, El-Sayed IH, Qian W, El-Sayed MA: cancer cells assemble and align gold nanorods conjugated to antibodies to produce highly enhanced, sharp, and polarized surface Raman spectra: a potential cancer diagnostic marker. Nano Lett 2007, 7:1591-1597.) Copyright 2007 American Chemical Society. b Dark-field illustration of HeLa cells (cancer) following treatment with Tf-conjugated GNRs (A, the GNRs and TEM photos of HeLa cells with Tf-Au NRs coated with multilayer polyelectrolyte lead to the orange/red dispersion (MLPs NRs) (B, the circle points out the GNRs). Reprinted with permission from (Ding H, Yong K-T, Roy I, Pudavar HE, Law WC, Bergey EJ, Prasad PN: Gold Nanorods Coated with Multilayer Polyelectrolyte as Contrast Agents for Multimodal Imaging. The Journal of Physical Chemistry C 2007, 111:12552-12557.) Copyright 2007 American Chemical Society. $\mathbf{c}$ Image of transmission with the indication of two ear blood vessels shown by two ears (A, dotted guide contour lines are provided to guide the eye), two-photon luminescence (TPL) image of GNRs (red dots) flowing through the blood vessels (B, autofluorescence from a hair root is the bright signal underneath the lower blood vessel.), transmission image (light blue) and overlay and a single-frame TPL image (C, a line-scan (white) superimposes two single nanorods (red spots)) (Wang et al. 2005b), Copyright (2005) National Academy of Sciences, U.S.A. d X-ray CT value and image of PEG-NRs compared with an iodine standard (A), three-dimensional distribution of PEG-NRs in tumors (arrows) after injection intratumorally in mice carrying bilateral MDA-MB-435 tumors(von Maltzahn et al. 2009; reprinted with permission from American Association for Cancer Research). e NIR transmission images of mice prior to treatment with plasmonic photothermal therapy (PPTT) and strength line NIR extinction scans at tumor sites for the regulation of PBS (green square), intravenous (orange triangle) and direct (red circle) pegylated gold nanorods administration. Reprinted from (Dickerson EB, Dreaden EC, Huang X, El-Sayed IH, Chu H, Pushpanketh S, McDonald JF, El-Sayed MA: Gold nanorod assisted near-infrared plasmonic photothermal therapy (PPTT) of squamous cell carcinoma in mice. Cancer Lett 2008, 269:57-66.), Copyright (2008), with permission from Elsevier 

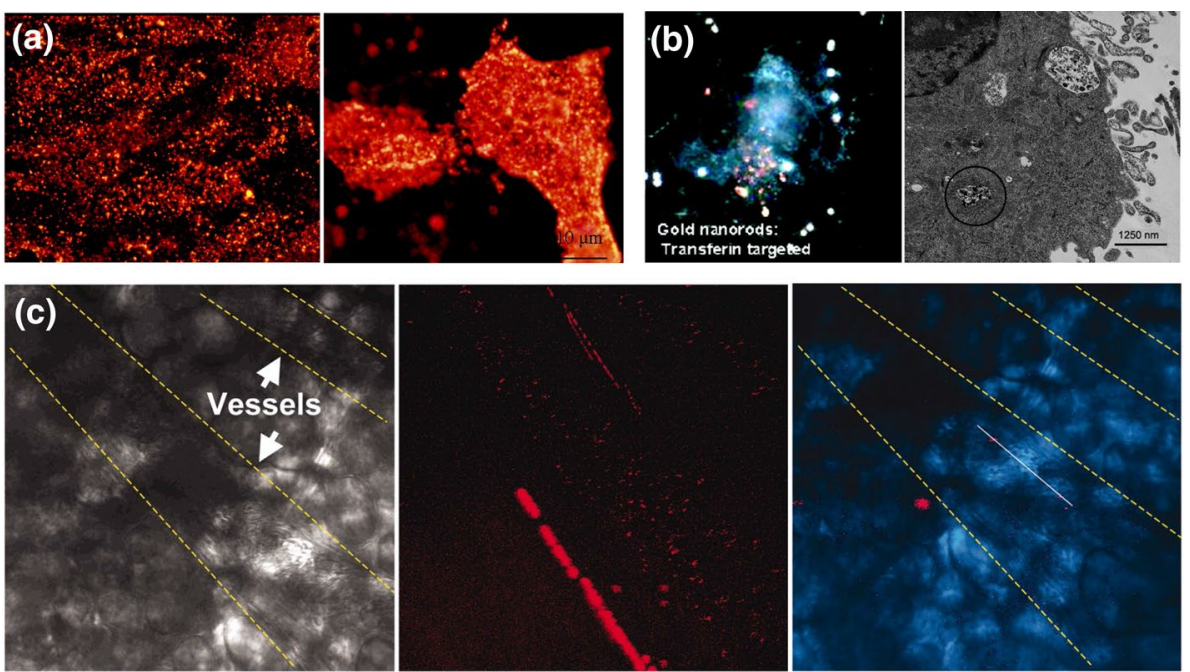

(d)
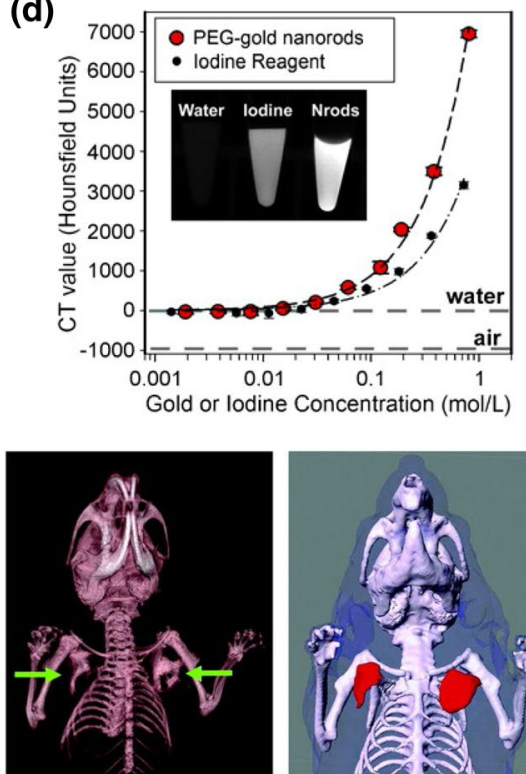

Fig. 2 (See legend on previous page.)

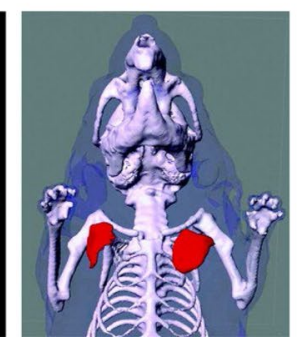

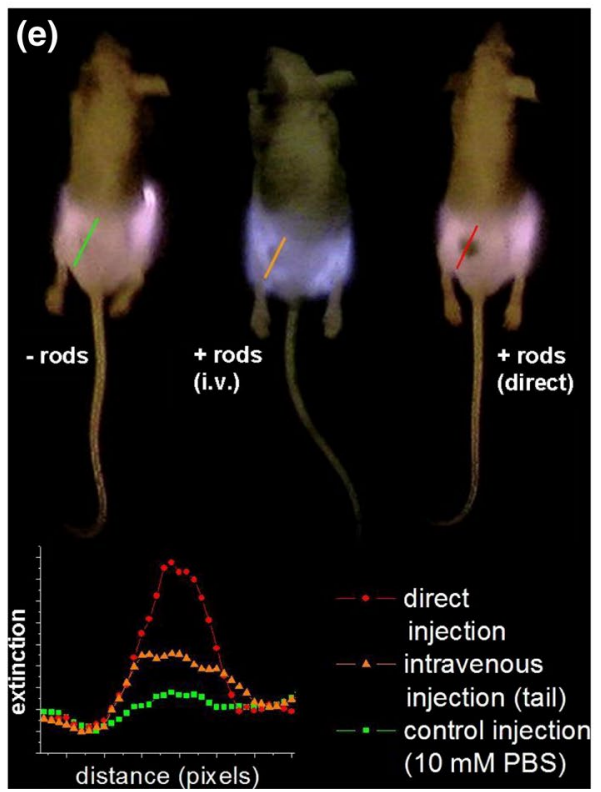

distance (pixels

was also reported that GNRs can be used to detect cancer cells located in deep tissues as a bright contrast agent for TPL imaging (Durr et al. 2007). The penetration depth is millimeters using OCT, the detection limit of GNRs is within the picomolar range and GNRs can be detected in resected human breast cancer (Oldenburg et al. 2009). For PAT, which is another new technology for imaging cells and deep tissues, GNR may produce photoacoustic contrast. Studies have shown that the photoacoustic image of stimulated endothelial cells combined with GNRs is much brighter than that of unstimulated cells, which indicates that GNRs can be used as an excellent contrast agent for early inflammation detection in vitro (Kim et al. 2007). In another in vivo sample, GNR binds with different aspect ratios to specifically target human epidermal growth factor receptor 2 (HER2) and EGFR antibodies, both of which are overexpressed in oral cancer cell lines OECMI and Cal 27, respectively. The aspect ratios of GNRs conjugated to HER2 or 
EGFR antibodies are tuned to produce SPR bands at 785 and $1000 \mathrm{~nm}$. These two probes can be used to attack HER2 or EGFR on all oral cancer cell lines in vivo and in vitro, and the irradiation wavelength of photoacoustic imaging (PAI) is switched between 800 and $1064 \mathrm{~nm}$. By comparing the radiation wavelength with the SPR band of the probe, PAI successfully tracked the corresponding molecular targets of oral cancer cell lines. Although no sample was used in the same mouse to identify molecular signatures for the two separate cells, this research will open up new avenues for multiple biomarker identification on cancer cells or the determination of a heterogeneous population of cancer cells in a lesion by merely changing the irradiation wavelength (Li et al. 2008b). Von Maltzahn and others explain that it is possible to use PEG-coupled GNRs (PEG-NRs) as dense X-ray absorbers for X-ray CT. It has anatomical three-dimensional (3D) resolution, rapid imaging speed, penetration of the whole body, and sufficient applications for clinical manifestations (von Maltzahn et al. 2009). They found that each mole of PEGNRs has approximately twice the X-ray magnification contrast compared with the with clinical iodine standard (Isovue-370). They were also able to obtain 3D tumor images after direct injection of about 3 pmol ( $1 \mu \mathrm{mol} \mathrm{Au})$ of PEG-NR (Fig. 2d). Near-infrared transmission imaging technology has also been reported to be used to track PEGylated GNR accumulation directly or after intravenous administration (Dickerson et al. 2008). As shown in Fig. 2e, HSC-3 tumor sites located in the left femurs of mice were optically tracked, and the tumor receiving direct pegylated GNR injection displayed twice the severity of NIR extinction as the tumor receiving the i.v. injection of pegylated GNRs, and more than seven times higher strength than the control tumor that received PBS.

There is no ideal molecular imaging method, and each has advantages and drawbacks. For example, optical imaging provides a high degree of precision and spatial resolution. However, it has low tissue penetration and is particularly vulnerable to noise due to photon scattering of visible light in tissue. While magnetic resonance imaging (MRI) and computed tomography have high imaging depth and spatial resolution, they have poor sensitivity. The combination of multiple imaging modalities will have synergistic benefits over any single modality. GNRs have also been studied for use in multimodal imaging. For example, indocyanine green-loaded mesoporous silica-coated GNRs were used as a dual mode imaging contrast agent for X-ray CT and fluorescence imaging (Luo et al. 2011; Xu et al. 2019). In addition, multifunctional probes were generated by conjugating Gd (III) ions on GNRs and used for both MRI and CT imaging (Aslan et al. 2020; Sun et al. 2011).

\section{GNRs as a phototherapeutic agent}

Cells are highly sensitive to changes in temperature, and cell death can result in temperatures above $42{ }^{\circ} \mathrm{C}$. Hyperthermia is an anti-cancer treatment that seeks to induce cell death by increasing the temperature of the cancer cells above normal levels. In the nucleus and cytoskeleton of the cells, excessive heating may cause protein denaturation or disruption of organized biomolecular assemblies (Pissuwan et al. 2008). Various photothermal agents, including aggregated gold nanoparticles, gold nanoshells, gold nanocages, GNRs, carbon nanotubes, graphene and copper sulphide $(\mathrm{CuS})$ nanoparticles, have been applied in vitro and in vivo for successful photothermal therapy so far (Alrahili et al. 2020; Chakravarty et al. 2008; Chen et al. 2007; Kim et al. 2006a; Li et al. 2008a; Li 
et al. 2010a; Mansour et al. 2019; Robinson et al. 2011; Zharov et al. 2005). GNRs have aroused their interest, since the light absorption range can be fine-tuned by adjusting the aspect ratio. Furthermore, GNRs has other benefits, including efficient large-scale synthesis, functionalization ease, and colloidal stability. Because of their advantages, including small size (30-50 nm), spherical, solid, narrow and adjustable SPR absorption in the near infrared field, hollow gold nanospheres (HGNs) are also becoming promising candidates for successful photothermal ablation therapy (Zhang 2010). Furthermore, it is stated to have a strong photothermal effect on cancer cells and melanoma cancer cells in vitro and in vivo (Farokhnezhad and Esmaeilzadeh 2019; Lu et al. 2009). It is, however, a challenge to establish a convenient mass production system for HGN, as well as high purity and efficient NIR spectrum window HGNs.

The strongly absorbed radiation can be efficiently converted into heat when nearinfrared light is irradiated into the GNRs, and by releasing their energy, the excited conduction band electrons can decay to the ground state. Because of the relatively low scattering and absorption of inherent tissue chromophores (Weissleder 2001), the use of near-infrared spectroscopy has advantages, such as a maximum light penetration depth of up to $10 \mathrm{~cm}$, depending on the type of tissue. The optimal aspect ratio of GNRs is typically 3.8 to 6 for effective molecular imaging and photothermal therapy using NIR spectroscopy (Sen et al. 2020; Wei et al. 2010). They can treat cancer effectively as an efficient thermotherapy, but targeting GNRs in particular can prevent photothermal ablation of normal tissues triggered by non-specific GNRs uptake more effectively.

Morales-Dalmau et al. recently investigated the photothermal therapy (PTT) potential of GNRs of various sizes. They found that the cytotoxicity of GNRs has little association with particle size, but increases with the total quantity of GNRs. Because of their higher cell uptake, smaller GNRs have a higher potential for photothermal ablation. While GNRs have a high optical absorption theoretically, they are randomly focused in human cells after injection. Under linear polarized NIR laser illumination, high absorption efficiency is difficult to attain and sustain. As a result, a high-energy NIR laser is required for photothermal ablation. During light-induced hyperthermia, a laser with a highpower density may harm or even "burn" healthy cells and tissues. As a result, spherical laser light can be used to generate a laser beam from all directions in order to improve the absorption potential of GNRs. Circular NIR light-induced hyperthermia has a very low energy threshold and does minimum damage to healthy cells and tissues (Eversole et al. 2020; Li et al. 2008a; Morales-Dalmau et al. 2018).

Tong et al. have studied the photothermal effect of folate-coupled GNRs on human malignant nasopharyngeal carcinoma (KB) cells through continuous wave (CW) NIR laser and femtosecond pulse laser irradiation (Tong et al. 2007). They observed that high folate receptor expression photopyrolysis of $\mathrm{KB}$ cells was more successful than standard NIH/3T3 cells with less folate receptors. In particular, folic acid-GNRs showed stronger thermal decomposition by fs pulse laser irradiation than with $\mathrm{CW}$ laser due to the increase of ultrafast electron dynamics during the plasmon-mediated heating process. A method of improving photothermal cancer treatment by targeting GNRs has been documented (Choi et al. 2011). GNRs is encapsulated by Pluronic-based nanocarriers (NC) instead of directly altering GNR, and the cellular absorption of GNR is greatly increased. In addition, a further increase in the uptake of GNRs-loaded cells, which is 
characterized by GNRs imaging, was achieved by using chitosan-coupled Pluronic-based nanocarriers (Chito-NC). Therefore, there are laser irradiation conditions in which chitosan-NC-GNRs have a very strong photothermal effect, followed by NC-GNRs, but no cell death is observed with direct GNRs administration. Moreover, nanocarrier-contained cellular absorption of GNR has a higher impact on cancer cells (SCC7) than normal cells (NIH/3T3), making the photothermal effect more selective for cancer cells. The above findings, therefore, indicate that the target GNRs can be used under low-energy harmless NIR laser irradiation as a selective and efficient photothermal agent (Jelveh and Chithrani 2011). It has also been confirmed by some research groups that GNRs can be used as a promising agent for cancer cell photothermolysis (Chen et al. 2010a; Huang et al. 2010). In our previous studies, we have also shown that plasmon nanohybrid based on GNRs generates strong localized hyperthermia due to the synergistic plasmonic effect of dual plasmon photothermal nanoagents, leading to elevated photothermal conversion efficiency (PCE) under low laser power density. These high PCE and strong localized electromagnetic field due to the influence of LSPR confer substantially higher in vivo synergistic tumor phototherapy (PDT/PTT) and photothermal destruction of bacterial pathogens/tumor cells (Younis et al. 2019).

Dickerson et al. proved the feasibility of using PEGylated GNR (PEG-NR) and a lightweight, compact, and inexpensive $\mathrm{CW}$ near-infrared laser at $808 \mathrm{~nm}$ for photothermal therapy to treat deep tissue malignant tumors in vivo plasmonic photothermal therapy. In mice with HSC-3 tumor xenografts, when PEG-NRs are injected intravenously, they preferentially accumulate at the tumor site because of the enhanced permeability and retention effect of tumor tissues (Dickerson et al. 2008). They found that the temperature of the tumor tissue with PEG-NR accumulation rose sharply to about $45{ }^{\circ} \mathrm{C}$ after $10 \mathrm{~min}$ of $1.7-1.9 \mathrm{~W} / \mathrm{cm}^{2}$ NIR laser irradiation. Finally, the absorption of tumor tissue by laser irradiation was greater than $57 \%$ for directly injected PEG-NRs, and about $25 \%$ for intravenously injected PEG-NRs, and no tumor absorption in all control groups was observed. Another study also stated that PEG-NRs can be used as highly efficient nano-heaters (von Maltzahn et al. 2009). As shown in Fig. 3, PEG-NRs showed a blood half-life of $\sim 17 \mathrm{~h}$ after i.v. injection into tumor-bearing mice $(20 \mathrm{mg} \mathrm{Au} / \mathrm{kg})$ and accumulation at $72 \mathrm{~h}$ at $\sim 7 \% \mathrm{ID} / \mathrm{g}$ at tumor sites. They found that laser irradiation rapidly heated tumors receiving PEGNRs to above $70{ }^{\circ} \mathrm{C}$, while the maximum surface temperature of mice injected with saline was around $40{ }^{\circ} \mathrm{C}$. Therefore, PEG-NR was administered intravenously to the tumor. Within 10 days after NIR laser irradiation, the injected dose disappeared completely $\left(810 \mathrm{~nm}, 2 \mathrm{~W} / \mathrm{cm}^{2}, 5 \mathrm{~min}\right)$, but the control group showed uninhibited tumor development. Therefore, compared with the control group, the survival time of the mice receiving PEG-NRs was more than 50 days, and $\sim 33$ days. Li et al. have also shown that the use of arginine-glycine-aspartic acid (RGD) peptide conjugated dendrimer modified GNR (dGNR) is efficient in vivo tumor targeting and photothermal therapy ( $\mathrm{Li}$ et al. 2010b). The RGD-dGNRs were examined at $47 \%$ in the blood at $3 \mathrm{~h}$ after injection and $\sim 17 \%$ in local tumor tissues at $6 \mathrm{~h}$ post-injection. They observed the disappearance of tumors in four mice from test group of ten after NIR laser irradiation $\left(808 \mathrm{~nm}, 24 \mathrm{~W} / \mathrm{cm}^{2}, 5 \mathrm{~min}\right)$ four times per month, once every week. 

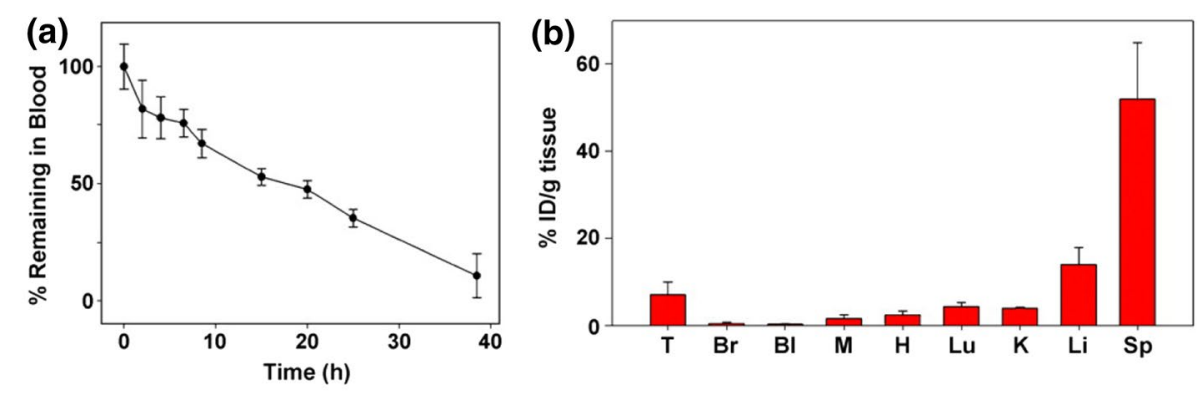

(c)

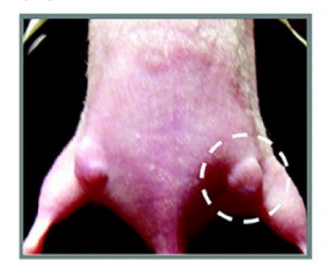

(d) $1.5 \mathrm{~min}$

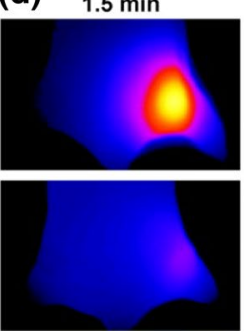

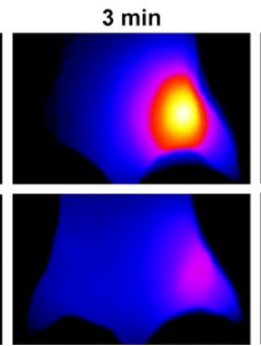

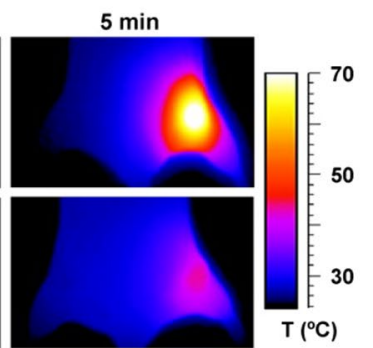

Fig. 3 Extended circulation time, inactive tumor targeting, and photothermal heating of passively targeted PEG-NRs in tumor-bearing mice. a Three mice carrying MDA-MB-435 tumors, 20 mg/kg PEG-NRs were i.v injected and blood was removed over time to control the clearance of PEG-NRs from circulation. $\mathbf{b}$ Biodistribution by PEG-NR at $72 \mathrm{~h}$ after i.v. administration, quantified via ICP-MSS ( $\mathrm{n}$ 3). M, muscle; $\mathrm{H}$, heart; Lu, lung; K, kidney; Li, liver; SP, spleen; T, tumor; Br, brain; Bl, bladder. c Saline or PEGNRs is i.v. injected (20 mg/kg) into mice carrying tumors of MDA-MB-435 on opposite flanks. The right flank was irradiated after $72 \mathrm{~h}$ with an $810-\mathrm{nm}$ laser diode $\left(2 \mathrm{~W} / \mathrm{cm}^{2}\right.$; beam size indicated by the dotted circle). $\mathbf{d}$ Thermographic surveillance of photothermal heating in PEG-NR-received (top) and saline-received (bottom) mice (von Maltzahn et al. 2009; reprinted with permission from American Association for Cancer Research)

\section{GNRs as an agent for simultaneous imaging and photothermal cancer therapy}

Due to the strong electric field on the surface, the absorption and scattering of electromagnetic radiation passing through the noble metal nanoparticles is greatly improved. These basic properties allow the production of new optically active reagents for simultaneous molecular imaging and photothermal cancer treatment. In vitro, gold nanorods have been shown to be a new type of contrast agent for molecular imaging and photothermal cancer treatment (Huang et al. 2006). In non-malignant epithelial cell line (HaCat) cultures and two malignant oral epithelial cell lines, nanorods were synthesized and conjugated to monoclonal anti-epidermal growth factor receptor (anti-EGFR) antibodies (HOC 313 clone 8 and HSC 3). Since EGFR is overexpressed on the plasma membrane of malignant cells, the anti-EGFR antibody-conjugated nanorods adhere to the surface of malignant cells with higher affinity. Using a laboratory microscope, it was observed that the intensely dispersed red light from the gold nanorods is visible in the dark area, which can easily visualize and distinguish malignant cells from non-malignant cells. After being exposed to the continuous red laser at $800 \mathrm{~nm}$, malignant cells need about half of the laser energy to be killed by light and heat, which is better than nonmalignant cells. As a result, successful cancer cell detection and targeted photothermal therapy were performed simultaneously.

GNRs are also the promising candidate for imaging-guided tumor PTT due to the $\mathrm{X}$-ray attenuation potential and simple surface functionalization. In the near infrared I (NIR-I) region of doxorubicin (DOX) loaded silica shell coated GNRs, two-photon 
imaging driven synergistic cancer chemotherapy/PTT (Zhang et al. 2012) has been reported. The thickness of the silica shell was effectively monitored within $30 \mathrm{~nm}$ to ensure the maximum effect of GNRs localized surface plasmon resonance (LSPR). While the high mesoporous silica shell surface area allowed high chemotherapeutic drug packing. Internalization and co-localization of the plasmon nanosystem and DOX were determined by two-photon (TP) imaging due to high two photon cross section of GNRs. A fraction of nanoparticles have been found to enter mitochondria, while most of them remain in lysosomes/endosomes. In addition to TP imaging, a sustained release of DOX from the silica shell was noticed under NIR lower power laser irradiation due to the LSPR effect of GNRs, but severe localized hyperthermia was reported under high power laser irradiation. Due to combined chemotherapy/PTT, both NIR laser excited drug releases and hyperthermia generation caused profound cellular killing of A549 cells in vitro. In addition to TP imaging, GNRs were also introduced by Rattoet et al. as contrast agents for X-ray computed tomography $(\mathrm{CT})$ and photoacoustic imaging (Ratto et al. 2016). In their study, polycationic GNRs were prepared, which were then further modified with (11-Mercaptoundecyl)-N, N, N-trimethylammonium bromide (MUTAB). Effective macrophage uptake of polycationic GNRs was demonstrated, maintaining their $>90 \%$ in vitro chemotactic activity and viability, respectively. These cells were effectively detected up to $1 \%$ by PAI and $10 \%$ by CT in whole blood due to the adequate amount of GNRs per macrophage, which is even below the characteristic quantity of leukocyte infiltration in the tumor microenvironment. A major photothermal destruction of macrophages was observed along with dual-modal CT/PAI imaging after incubation with GNRs under continuous wave laser excitation, whereas no clear damage was observed to macrophages by continuous wave alone. These results indicated the capability of GNRs both as a contrast as well as a photothermal agent for imaging-guided tumor PTT.

In addition to the plasmon nanosystem, the magnetic plasmon nanosystem for dual modal magnetic resonance imaging (MRI)/PAI-guided chemo/PTT in vivo was developed. They inserted GNRs, which were then further filled with DOX, into the porous iron oxide shell. Magnetically targeted delivery of DOX in response to dual $\mathrm{pH}$ stimuli and localized hyperthermia produced by GNRs under NIR-I laser excitation was achieved due to the super paramagnetic character of iron oxide (Fig. 4a) (Huang et al. 2016). In vivo dual-modal PAI/MRI was performed by intravenous injection of magnetic plasmon nanocapsules into 4T1 tumors carrying mice. A significant contrast at the tumor site was observed for both $T_{2}$-weighted MRI and PAI after post-injection of nanocapsules, which improved significantly under magnetic field guidance (Fig. 4b, c). Total tumor eradication was seen in $4 \mathrm{~T} 1$ tumor mice with $100 \%$ survival over a 1 month period under dual-modal MRI/PAI guidance. Synergistic chemotherapy/PTT has been strongly linked to such a remarkable clinical response, which is considerably higher than the single treatment modality of either PTT or chemotherapy. In contrast to passive tumor accumulation, under the guidance of single photon emission CT (SPECT)/ PAI, Zhang's group developed GNRs-based theranostic nanosystems, which can actively target tumor angiogenesis as well as give dual-modal tumor chemo/PTT in the NIR-I region. 


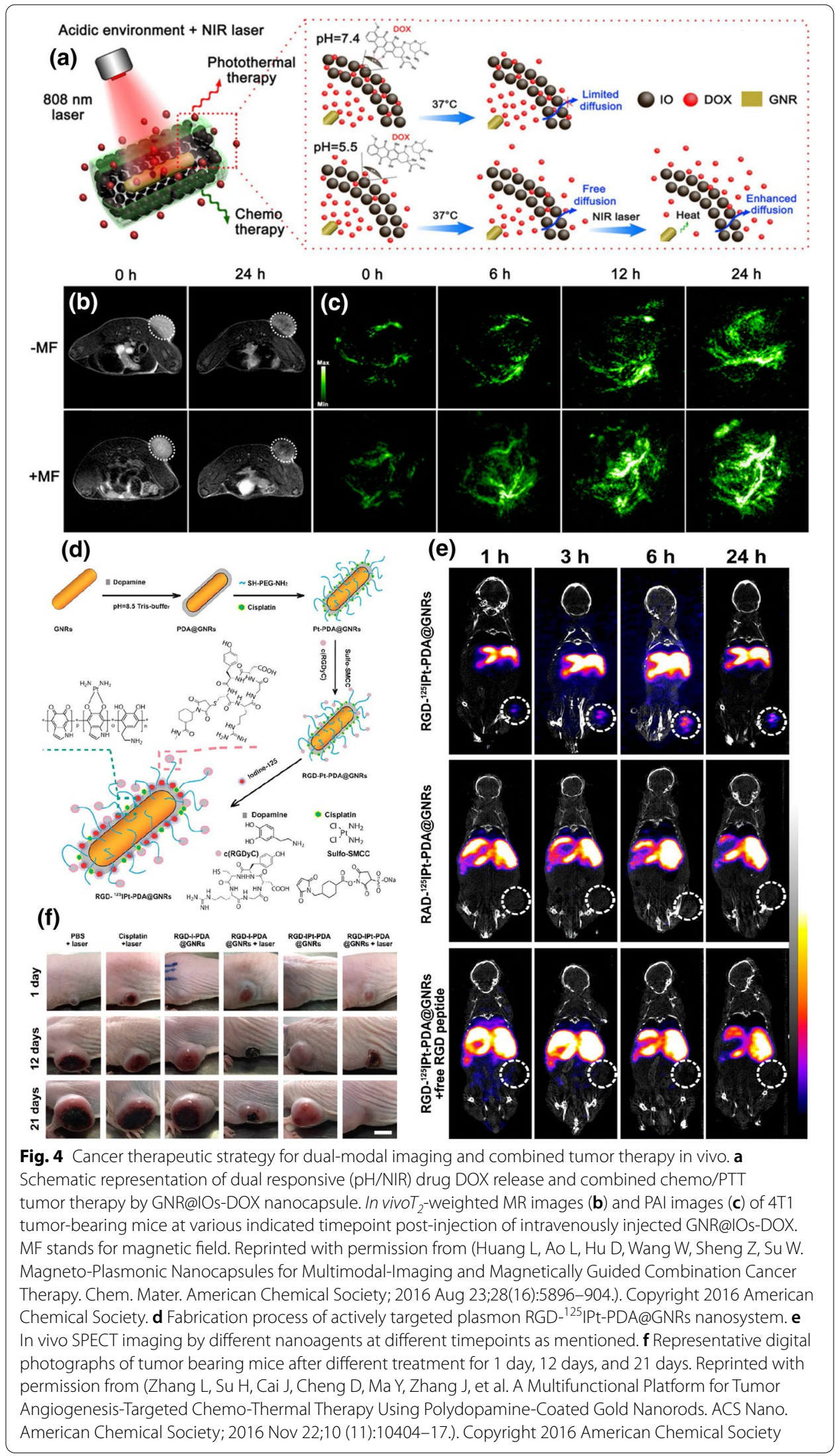


In their work, actively targeted plasmon nanosystems (RGD- ${ }^{125}$ IPt-PDA@GNRs) were developed by polydopamine (PDA) GNR coating, chemotherapeutic drug cisplatin loading, RGD peptide conjugating, and finally chelator-free iodine-125 radio labeling (Fig. 4d) (Zhang et al. 2016). Due to effective targeting against tumor angiogenesis and strong affinity for alpha- $\beta 3$ integrin, RGD- ${ }^{125}$ IPt-PDA@GNRs selectively accumulated in the tumor as revealed by in vivo SPECT and PAI, respectively. Meanwhile, under NIR-I laser irradiation, such an extremely tumor-enriched plasmon nanosystem leads to significant tumor ablation in tumor-bearing H1299 mice due to synergistic antitumor effects induced by collaborative chemo/PTTT (Fig. 4e, f). In addition to dual-modal chemo/PTT, silica coated GNRs were also shown to be conjugated with organic photosensitizer dye (indocyanine green, ICG) and loaded with 5-fluorouracil (5-FU), multimodal imaging-driven tri-modal chemo/PTT/photodynamic therapy, while 5-FU was effectively released under $\mathrm{pH}$ stimuli and NIR-I laser irradiation, promoting the killing of chemotherapy tumors. Similarly, under laser irradiation, high photothermal effect and singlet oxygen production were also monitored, resulting in significant tumor cell killing (Fang et al. 2017). Moreover, multimodal (TP luminescence, fluorescence, photothermal, PA) imaging in vivo was adequately led by $\mathrm{Au@SiO}{ }_{2}$-ICG-5-FU, resulting in remarkable tumor growth inhibition in A375 tumor bearing mice. It is noteworthy to mention that tri-modal therapy demonstrated much superior effects of antitumor than any single modality. Such a multifunctional plasmon nanocomplex is highly beneficial for stimuli responsive drug delivery as well as effective tumor diagnosis and treatment. In a subsequent analysis, dual stimuli $\mathrm{pH} /$ matrix metalloproteinases (MMPs) sensitive actively targeted GNRs-based plasmon theranostic nanoprobe was also documented by Zhao's group for fluorescence imaging driven PTT (Zhao et al. 2017). Similarly, bacterial-like GNRs were also reported by Zhang and co-workers for synergistic chemo/PTT of $4 \mathrm{~T} 1$ breast cancer under the guidance of dual-modal positron emission tomography (PET)/PA imaging (Zhang et al. 2016). Radiology (MR/X-ray)-guided theranostic GNRs for PTT of colorectal cancer liver metastasis were shown by Parchur et al. (Parchur et al. 2018) Qiu et al. achieved activatable PDT/PTT using protoporphyrin (PpIX) modified GNRs covalently conjugated with responsive peptide metalloproteinases-2 (MMP-2) (Qiu et al. 2017). As GNRs were in close proximity due to the peptide, the fluorescence as well as the photoactivity of PpIX were effectively quenched due to the LSPR effect. However, strong PpIX fluorescence was observed after MMP-2 peptide hydrolysis at the tumor site, leading to the production of singlet oxygen for photodynamic tumor cell killing (Fig. 5a, b). On the other hand, under NIR-I laser irradiation, a significant temperature increase was reported in the tumor region for $5 \mathrm{~min}$, which is adequate for controlled ablation of the tumor cells. Such a combination of PDT/PTT induced a deep reduction in the growth of tumor cells in SCC-7 tumor-bearing mice without obvious systemic toxicity. Besides synergistic chemo/PTT or phototherapy, Duan et al. demonstrated tri-modal chemo/PTT/gene therapy of glioma tumor under dual-modal CT/PA imaging by GNRs theranostic nanoplatform (Fig. 5c) (Duan et al. 2017). Silica coated GNRs were incorporated with quantum dots, while DOX was loaded into the silica shell 

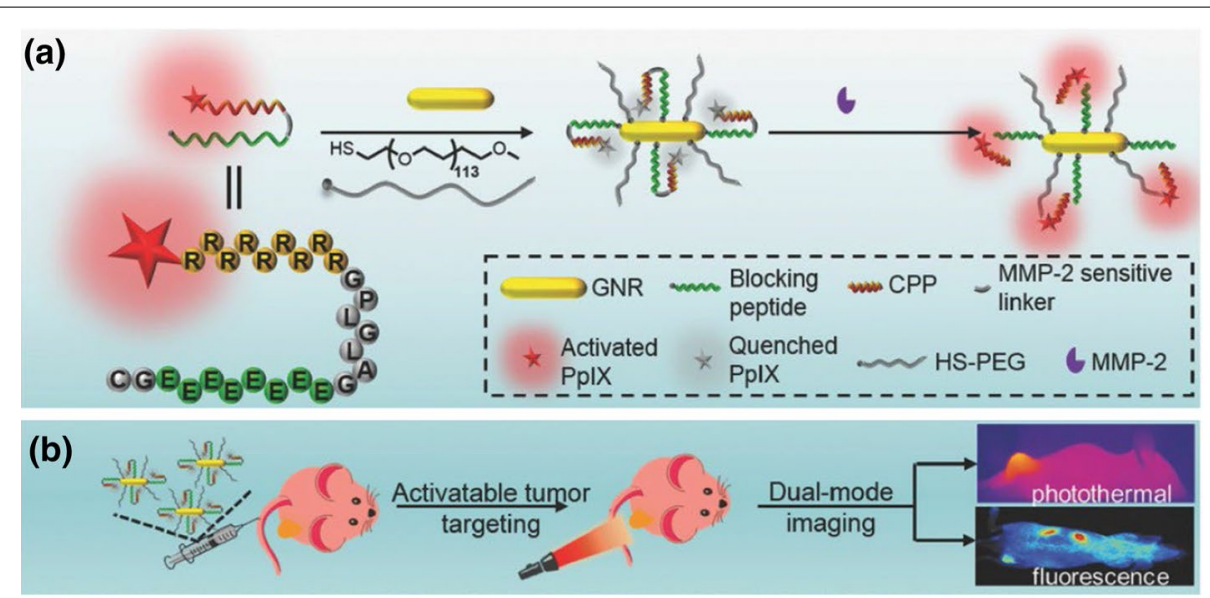

(c)

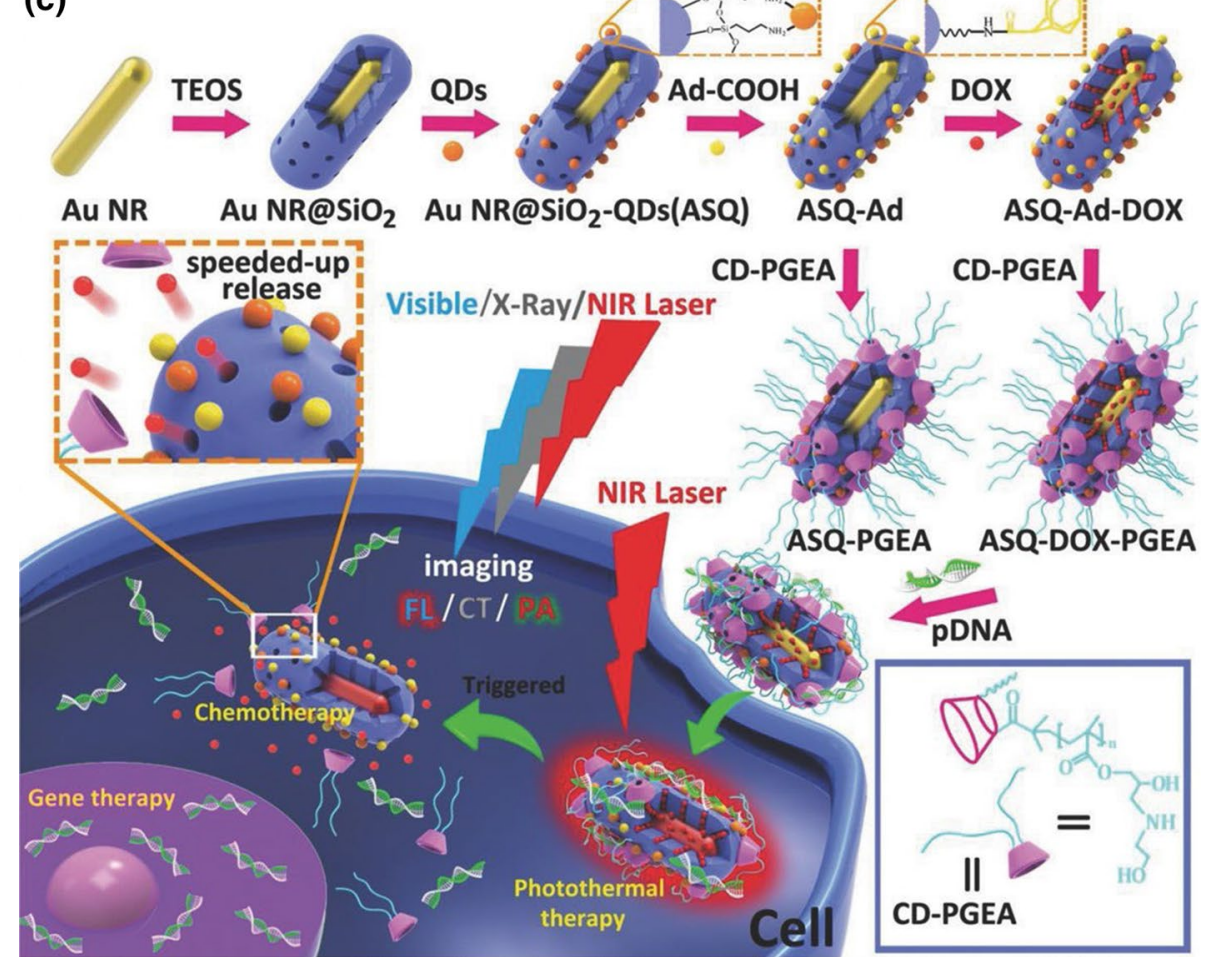

Fig. 5 Procedures of the multifunctional and activatable nanoplatform on the basis of the gold nanorods. a Fabrication process of the GNRs-based theranostic nanoplatform. $\mathbf{b}$ Representation of the dual-modal imaging-guided synergistic activatable PTT/PDT. Reprinted with permission from (Qiu W-X, Liu L-H, Li S-Y, Lei Q, Luo G-F, Zhang X-Z. ACPI Conjugated Gold Nanorods as Nanoplatform for Dual Image Guided Activatable Photodynamic and Photothermal Combined Therapy In Vivo. Small Weinh. Bergstr. Ger. 2017 May;13(18).). Copyright 2017 John Wiley and Sons. c Diagramatic illustration of the design and operational strategy of multimodal imaging-guided plasmon nanotheranostic complex. Reprinted with permission from (Duan $\mathrm{S}$, Yang Y, Zhang C, Zhao N, Xu F-J. NIR-Responsive Polycationic Gatekeeper-Cloaked Hetero-Nanoparticles for Multimodal Imaging-Guided Triple-Combination Therapy of Cancer. Small. 2017;13(9):1603133.). Copyright 2016 John Wiley and Sons

and then sealed with a cationic gatekeeper and DNA complex. Photothermal ablation of tumor cells and detach gatekeeper was triggered by localized hyperthermia induced by GNRs under NIR-I laser irradiation, resulting in a regulated delivery of DOX and gene 
due to the photothermal impact. This work presented a promising design of multifarious plasmon nanotheranostic complex for simultaneous tumor diagnosis and collaborative tumor therapy with negligible cytotoxicity, suggesting potential for clinical translation.

\section{Merits and limitations of GNRs}

Gold nanorods have so demonstrated outstanding optical characteristics, making them suitable for a broad range of applications, including cancer diagnosis and therapy, which has lately gained popularity. The ultimate goal of this field is to create and develop effective GNR materials and nanodevices at the nanoscale. Exploring GNR's biomedical engineering applications may provide a solid foundation in biochemistry, biocompatibility, molecular biology, and materials science. This new information will enable the development of a wide range of nanoprobes and nanodevices for tumor molecular imaging and targeted treatment. Surface functionalization improves GNR biocompatibility and biodistribution. GNR-based nanoprobes and nanodevices will contribute to therapeutic applications in the future due to their extraordinary application potential.

Despite the fact that nanotechnology has recently received a lot of attention, we feel that there are still certain challenges that need to be resolved before GNRs may be employed in photothermal treatment. For example, while current in vitro and in vivo results are encouraging, further in vivo research on therapeutic efficacy, biocompatibility, and bio-distribution is needed to make these approaches more therapeutically useful. Toxicity, biodistribution, and the fate of nanoparticles following in vivo treatment are the most important factors. In addition to toxicity issue, there are a number of additional concerns that must be addressed, such as GNR stability, blood retention following in vivo delivery, tissue distribution, and metabolism. Only a few early stage preclinical trials with GNRs have been conducted so far. As a result, more study is needed to address all of the aforementioned problems.

\section{Conclusion}

The development in the preparation of the seed-mediated growth method for GNRs and the application of GNRs in imaging and photothermal therapy has been reviewed. The potential medicinal applications of GPRs in nanoform are summarized in Table 1. Clearly, due to their strong absorption and scattering of near-infrared radiation, there has been a lot of progress in the synthesis of GNRs and their use in simultaneous imaging/therapy. The toxicity associated with the remaining CTAB is the main concern about the clinical application of GNRs. We summarized several recent surface modification techniques for gold nanorods. These methods are useful in improving the properties of gold nanorods and in solving the issues caused by CTAB. Most of the toxicity data for GNRs has so far been obtained from in vitro cell studies. Therefore, using existing animal models, it is important to obtain more in vivo toxicological data for GNRs. Polymer functionalization such as PEG increases the half-life of GNRs in blood circulation and targeting agent conjugation allows them accumulate further in target tissues. There will 
Table 1 Summary of the potential medicinal applications of GNRs in nanoform, as well as the main endpoints

\begin{tabular}{|c|c|c|c|}
\hline Type of nanomaterials & Research model & Main findings & References \\
\hline Gold nanorods & $\begin{array}{l}\text { HaCaT cells, HOC } 313 \text { clone } \\
8 \text { cells, HSC } 3 \text { cells }\end{array}$ & $\begin{array}{l}\text { The strongly scattered red } \\
\text { light from gold nanorods } \\
\text { clearly visualizes and } \\
\text { differentiates cancerous } \\
\text { cells from nonmalig- } \\
\text { nant cells. It has been } \\
\text { discovered that after } \\
\text { being exposed to a } \\
\text { continuous red laser at } \\
800 \text { nm, malignant cells } \\
\text { require approximately } \\
\text { half the laser energy to } \\
\text { be photothermally killed } \\
\text { as nonmalignant cells }\end{array}$ & (Huang et al. 2006) \\
\hline Gold nanorods & HeLa cells & $\begin{array}{l}\text { The extraction using } \\
\text { a chloroform phase } \\
\text { containing PC was found } \\
\text { to be a useful method for } \\
\text { substituting CTAB with } \\
\text { other capping agents, } \\
\text { such as PC }\end{array}$ & (Takahashi et al. 2006) \\
\hline Gold nanoparticles & Nude mice & $\begin{array}{l}\text { LOIS can detect gold } \\
\text { nanorods in vivo at low } \\
\text { concentrations, and the } \\
\text { nanoparticles can be } \\
\text { modified to improve } \\
\text { the diagnostic power of } \\
\text { optoacoustic imaging }\end{array}$ & (Eghtedari et al. 2007) \\
\hline $\begin{array}{l}\text { Plasmon-resonant gold } \\
\text { nanorods }\end{array}$ & Adherent human KB cells & $\begin{array}{l}\text { When irradiated with the } \\
\text { longitudinal plasmon } \\
\text { resonance of the } \\
\text { nanorods, the nanorods } \\
\text { make tumor cells very } \\
\text { sensitive to photother- } \\
\text { mal damage, causing } \\
\text { widespread blistering of } \\
\text { cell membranes under } \\
\text { laser energy as low as } \\
44 \mathrm{~W} / \mathrm{cm}^{2}\end{array}$ & (Huff et al. 2007) \\
\hline Gold nanorods & $\begin{array}{l}\text { Human umbilical vein } \\
\text { endothelial cells }\end{array}$ & $\begin{array}{l}\text { The use of bioconjugated } \\
\text { gold nanorods for } \\
\text { photoacoustic imaging } \\
\text { of inflammation }\end{array}$ & (Kim et al. 2007) \\
\hline $\begin{array}{l}\text { Transferrin-conjugated } \\
\text { gold nanorods }\end{array}$ & HeLa cells & $\begin{array}{l}\text { After a few hours of } \\
\text { incubation with the } \\
\text { nanorods, the cancer } \\
\text { cells may be clearly } \\
\text { observed. Simultane- } \\
\text { ous imaging and highly } \\
\text { targeted PTT may be } \\
\text { accomplished without } \\
\text { causing any harming to } \\
\text { the healthy tissue that } \\
\text { is exposed to the laser } \\
\text { beam }\end{array}$ & (Li et al. 2008a) \\
\hline Gold nanorods & $\begin{array}{l}\text { OECM1 cells, Cal27 cells, } \\
\text { mice }\end{array}$ & $\begin{array}{l}\text { In vitro and in vivo mouse } \\
\text { model imaging investi- } \\
\text { gations were carried out, } \\
\text { with contrast enhance- } \\
\text { ments of up to } 10 \mathrm{~dB} \text { and } \\
3.5 \mathrm{~dB} \text {, respectively }\end{array}$ & (Li et al. 2008b) \\
\hline
\end{tabular}


Table 1 (continued)

\begin{tabular}{|c|c|c|c|}
\hline Type of nanomaterials & Research model & Main findings & References \\
\hline $\begin{array}{l}\text { CTAB/PAA/PAH capped } \\
\text { gold nanorod }\end{array}$ & $\begin{array}{l}\text { Human colon carcinoma } \\
\text { cells (HT-29) }\end{array}$ & $\begin{array}{l}\text { The apparent cytotoxicity } \\
\text { is due to free CTAB in } \\
\text { solution. The addition } \\
\text { of polymers to the } \\
\text { nanorods significantly } \\
\text { lowers cytotoxicity }\end{array}$ & (Alkilany et al. 2009) \\
\hline $\begin{array}{l}\text { Polymeric entrapped thio- } \\
\text { coated gold nanorods }\end{array}$ & $\begin{array}{l}\text { Mouse fibroblasts } \\
\text { (Balb/3T3) }\end{array}$ & $\begin{array}{l}\text { In our in vitro model, } \\
\text { signals with satisfying } \\
\text { signal-to-noise ratios } \\
\text { were obtained down } \\
\text { to concentrations of } \\
11 \mathrm{mM} \text {, equivalent to } \\
\text { subtoxic concentration }\end{array}$ & (Franchini et al. 2010) \\
\hline Gold nanorods & $\begin{array}{l}\text { Human prostate cancer cell } \\
\text { line (PC3-PSMA) }\end{array}$ & $\begin{array}{l}\text { The model was expanded } \\
\text { to examine at the effect } \\
\text { of preferential binding of } \\
\text { gold nanorods to cancer } \\
\text { cells vs non-malignant } \\
\text { cells, as well as a slight } \\
\text { variation in cell damage } \\
\text { activation energy }\end{array}$ & (Huang et al. 2010) \\
\hline $\begin{array}{l}\text { RGD-conjugated } \\
\text { dendrimer-modified gold } \\
\text { nanorods }\end{array}$ & $\begin{array}{l}\text { MCF-7 cells, HUVEC cells, } \\
\text { A375 cells, mice }\end{array}$ & $\begin{array}{l}\text { Under NIR laser irradiation, } \\
\text { the RGD-conjugated } \\
\text { dGNR nanoprobes } \\
\text { are not cytotoxic, can } \\
\text { precisely target tumor } \\
\text { cells and vascular cells } \\
\text { inside tumor tissues, and } \\
\text { have selective damaging } \\
\text { effects on melanoma } \\
\text { cells. They can even } \\
\text { cause a portion of a } \\
\text { tumor's tissues to vanish } \\
\text { in mice }\end{array}$ & (Li et al. 2010b) \\
\hline $\begin{array}{l}\text { Gold nanorods coated } \\
\text { with polyamidoamine } \\
\text { dendrimer }\end{array}$ & MCF-7 cells & $\begin{array}{l}\text { Gold nanorods have a tun- } \\
\text { able absorbance band } \\
\text { at } 850 \mathrm{~nm} \text {, which may } \\
\text { be used to track their } \\
\text { position in cancer cells. } \\
\text { They can also be utilized } \\
\text { to boost the produc- } \\
\text { tion of brcaa1-shRNA in } \\
\text { MCF-7 cells and limit the } \\
\text { development of MCF-7 } \\
\text { cells when exposed to } \\
\text { local infrared irradiation }\end{array}$ & (Cui et al. 2011) \\
\hline $\begin{array}{l}\text { Folic acid-conjugated } \\
\text { silica-modified GNRs }\end{array}$ & MGC803 cells, nude mice & $\begin{array}{l}\text { Folic acid-conjugated } \\
\text { silica-modified GNRs } \\
\text { display extremely selec- } \\
\text { tive targeting, improved } \\
\text { RT and PTT effects } \\
\text { on MGC803 gastric } \\
\text { cancer cells, as well as } \\
\text { substantial X-ray attenua- } \\
\text { tion for in vivo X-ray and } \\
\text { computed tomography } \\
\text { (CT) imaging }\end{array}$ & (Huang et al. 2011) \\
\hline
\end{tabular}


Table 1 (continued)

\begin{tabular}{|c|c|c|c|}
\hline Type of nanomaterials & Research model & Main findings & References \\
\hline Gold nanorods & $\begin{array}{l}\text { Macrophage cell line } \\
\text { (Ana-1 cells) and E knock- } \\
\text { out (Apo E) mouse }\end{array}$ & $\begin{array}{l}\text { Even at low GNRs concen- } \\
\text { trations and NIR powers, } \\
\text { in vitro photothermal } \\
\text { ablation therapy with } \\
\text { GNRs demonstrated } \\
\text { considerable cell-killing } \\
\text { effectiveness of mac- } \\
\text { rophages. Furthermore, } \\
\text { in vivo experiments } \\
\text { showed that GNRs are } \\
\text { useful for in vivo imaging } \\
\text { and photothermal treat- } \\
\text { ment of inflammatory } \\
\text { macrophages in femoral } \\
\text { artery restenosis }\end{array}$ & (Qin et al. 2015) \\
\hline Polycationic gold nanorods & $\begin{array}{l}\text { J774a.1 monocyte } \\
\text { /macrophagic cells }\end{array}$ & $\begin{array}{l}\text { Polycationic gold nanorods } \\
\text { are efficiently and } \\
\text { reproducibly taken up } \\
\text { by tumor-tropic cells } \\
\text { such as macrophages, } \\
\text { preserving their survival } \\
\text { as well as more than } 90 \% \\
\text { of their inherent chemot- } \\
\text { actic activity in vitro }\end{array}$ & (Ratto et al. 2016) \\
\hline $\begin{array}{l}\text { silica-coated gold } \\
\text { nanorods (GNR@SiO })_{2}, \\
\text { Indocyanine Green (ICG), } \\
\text { 5-fluorouracil (5-FU) }\end{array}$ & A375 cells, mice & 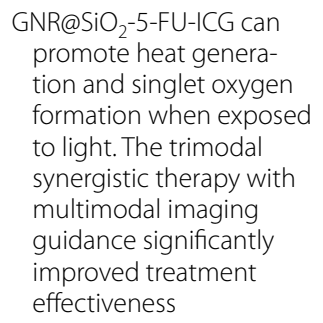 & (Fang et al. 2017) \\
\hline Gold nanorods & $\begin{array}{l}\text { Immunodeficient BALB/C } \\
\text { mice }\end{array}$ & $\begin{array}{l}\text { Spectroscopy and } \\
\text { transmission electron } \\
\text { microscopy are utilized } \\
\text { in this work to show that } \\
\text { GNRs reshape in vitro } \\
\text { and in vivo following CW } \\
\text { irradiation, reducing their } \\
\text { absorption efficiency }\end{array}$ & (Harris-Birtill et al. 2017) \\
\hline Gold nanorods & Mice & $\begin{array}{l}\text { In vivo imaging of single } \\
\text { gold nanorods flowing in } \\
\text { mouse ear blood arteries } \\
\text { demonstrates the use of } \\
\text { gold nanorods as two- } \\
\text { photon luminescence } \\
\text { imaging agents }\end{array}$ & (Villar-Alvarez et al. 2018) \\
\hline Aptamer gold nanorods & KB cancer cells & $\begin{array}{l}\text { The samples were irradi- } \\
\text { ated with an } 845 \mathrm{~nm} \\
\text { light-emitting diode, the } \\
\text { targeted KB cells demon- } \\
\text { strated } 80 \% \text { cell mortality } \\
\text { when compared to } \\
\text { the unirradiated and } \\
\text { aptamer-free controls. } \\
\text { Based on Apt-GNRs'low } \\
\text { toxicity, biocompatibil- } \\
\text { ity, and selectivity, the } \\
\text { suggested nanoplatform } \\
\text { offers substantial poten- } \\
\text { tial in vivo as a cancer } \\
\text { therapeutic }\end{array}$ & (Noh et al. 2019) \\
\hline
\end{tabular}


Table 1 (continued)

\begin{tabular}{|c|c|c|c|}
\hline Type of nanomaterials & Research model & Main findings & References \\
\hline Gold nanorods & $\begin{array}{l}\text { Malignant (MCF-7) breast } \\
\text { cell lines }\end{array}$ & $\begin{array}{l}\text { Multiple variations were } \\
\text { evaluated, including } \\
\text { HP concentration (10\% } \\
\text { and } 100 \%) \text {, heating } \\
\text { modalities, laser induc- } \\
\text { tion period (10, 30, and } \\
60 \text { min), and cell line } \\
\text { type (normal and malig- } \\
\text { nant); all of these factors } \\
\text { might be contentious }\end{array}$ & (Hashemi et al. 2019) \\
\hline $\begin{array}{l}\text { Plasmonic nanohybrid } \\
\text { with gold nanorods and } \\
\text { graphene oxide }\end{array}$ & $\begin{array}{l}\text { HeLa tumor cells, normal } \\
\text { human cell line (HUVECs), } \\
\text { mice }\end{array}$ & $\begin{array}{l}\text { The plasmonic AuNRs/ } \\
\text { GO nanohybrid is a } \\
\text { stand-alone PTA that can } \\
\text { conduct simultaneous } \\
\text { antibacterial/anticancer } \\
\text { PTT for just } 5 \text { min under } \\
\text { low power NIR laser acti- } \\
\text { vation, with no systemic } \\
\text { adverse effects }\end{array}$ & (Younis et al. 2019) \\
\hline $\begin{array}{l}\text { Mesoporous silica-coated } \\
\text { gold nanorods }\end{array}$ & MDR SW620/Ad300 cells & $\begin{array}{l}\text { The nanocomposite dem- } \\
\text { onstrated very effective } \\
\text { photothermal conver- } \\
\text { sion in the NIR region, } \\
\text { a pH and NIR induced } \\
\text { drug release profile, and } \\
\text { an increase in DOX intra- } \\
\text { cellular accumulation } \\
\text { and cytotoxicity in MDR } \\
\text { SW620/Ad300 cells }\end{array}$ & (Li et al. 2020a) \\
\hline $\begin{array}{l}\mathrm{GNRS} / \mathrm{mSiO}_{2} / \mathrm{PHIS} / \mathrm{TPGS} / \\
\text { DOX) }\end{array}$ & $\begin{array}{l}\text { SW620/Ad300 tumor bear- } \\
\text { ing mice }\end{array}$ & $\begin{array}{l}\text { Most notably, as compared } \\
\text { to other control groups } \\
\text { using either chemo- or } \\
\text { photothermal treatment } \\
\text { alone on SW620/Ad300 } \\
\text { tumor bearing mice, } \\
\text { the nanocomposite } \\
\text { demonstrated the most } \\
\text { effective antitumor activ- } \\
\text { ity with no clear systemic } \\
\text { damage }\end{array}$ & (Jiang et al. 2020) \\
\hline $\begin{array}{l}\text { Gold nanorods (GNRs) on } \\
\text { silver-island film }\end{array}$ & $\begin{array}{l}\text { HeLa human cervix } \\
\text { adenocarcinoma cells, } \\
\text { exosome, plasma }\end{array}$ & $\begin{array}{l}\text { Gold nanorods (GNRs) } \\
\text { on silver-island film can } \\
\text { produce } 360 \text {-fold AF647 } \\
\text { molecule fluorescence } \\
\text { enhancement compared } \\
\text { to glass. Utilizing the } \\
\text { enhanced fluorescence } \\
\text { from the substrate, } \\
\text { GNRs attached with the } \\
\text { biomolecules and create } \\
\text { a sandwich immunoas- } \\
\text { say that can significantly } \\
\text { detect human CD63 } \\
\text { antigen on the exosome }\end{array}$ & (Naseer et al. 2021) \\
\hline
\end{tabular}

also be a need to determine the fate of postphotothermal therapy GNRs. Only a few early stage preclinical studies have been conducted with GNRs at present. In order to address all of the above issues, further research is, therefore, needed. After resolving these problems, clinical application of GNR-based theranostic agents will be feasible.

Acknowledgements

We are grateful to instrument analysis center of Shenzhen University. 


\section{Authors' contributions}

NUK and LS conceived the idea. NUK, JL, and MRY wrote the manuscript. NUK, LS, and XL compiled the final draft and did the editing. LS was involved in funding. All authors read and approved the final manuscript.

\section{Funding}

This study was financially supported by National Natural Science Foundation of China (Grant No. 31870825), the Shenzhen Bureau of Science, Technology and Information (Nos. JCYJ20170412110026229), and Shenzhen-Hong Kong Institute of Brain Science-Shenzhen Fundamental Research Institutions, 2019SHIBS0003.

\section{Availability of data and materials}

Not applicable.

\section{Declarations}

Ethics approval and consent to participate

Not applicable.

\section{Consent for publication}

Figures were reproduced with permissions from the publishers.

\section{Competing interests}

The authors have declared no conflict of interest.

\section{Author details}

${ }^{1}$ College of Life Science and Oceanography, Shenzhen University, Shenzhen 518071, People's Republic of China. ${ }^{2}$ Brain Disease and Big Data Research Institute, Shenzhen University, Shenzhen 518071, People's Republic of China. ${ }^{3}$ Shenzhen Key Laboratory of Marine Biotechnology and Ecology, Shenzhen 518071, People's Republic of China. ${ }^{4}$ Marshall Laboratory of Biomedical Engineering International Cancer Center Laboratory of Evolutionary Theranostics (LET), School of Biomedical Engineering, Shenzhen University Health Science Center, Shenzhen 518060, China.

Received: 3 April 2021 Accepted: 12 July 2021

Published online: 23 July 2021

\section{References}

Aazam ES, Zaheer Z (2020) Rose cyanidin 3,5-di-O-glucoside-assisted gold nanoparticles, their antiradical and photocataIytic activities. J Mater Sci Mater Electron 31(11):8780-8795

Ali MRK, Panikkanvalappil SR, El-Sayed MA (2014) Enhancing the efficiency of gold nanoparticles treatment of cancer by increasing their rate of endocytosis and cell accumulation using rifampicin. J Am Chem Soc 136(12):4464-4467

Alkilany AM, Nagaria PK, Hexel CR, Shaw TJ, Murphy CJ, Wyatt MD (2009) Cellular uptake and cytotoxicity of gold nanorods: molecular origin of cytotoxicity and surface effects. Small 5(6):701-708

Alrahili M, Peroor R, Savchuk V, McNear K, Pinchuk A (2020) Morphology dependence in photothermal heating of gold nanomaterials with near-infrared laser. J Phys Chem C Am Chem Soc. 124(8):4755-4763

Apte A, Bhaskar P, Das R, Chaturvedi S, Poddar P, Kulkarni S (2015) Self-assembled vertically aligned gold nanorod superlattices for ultra-high sensitive detection of molecules. Nano Res 8(3):907-919

Aslan N, Ceylan B, Koç MM, Findik F (2020) Metallic nanoparticles as X-Ray computed tomography (CT) contrast agents: a review. J Mol Struct 1219:128599

Auguste M, Mayall C, Barbero F, Hočevar M, Alberti S, Grassi G et al (2021) Functional and morphological changes induced in mytilus hemocytes by selected nanoparticles. Nanomaterials 11(2):470

Bai X, Wang Y, Song Z, Feng Y, Chen Y, Zhang D et al (2020) The basic properties of gold nanoparticles and their applications in tumor diagnosis and treatment. Int J Mol Sci 21(7):2480

Ban GJ, Fu XL, Peng ZJ (2014) Gold nanorods: from synthesis to optical properties. Key Eng Mater 602-603:993-997

Becker J, Zins I, Jakab A, Khalavka Y, Schubert O, Sönnichsen C (2008) Plasmonic focusing reduces ensemble linewidth of silver-coated gold nanorods. Nano Lett 8(6):1719-1723

Boyer J-C, Manseau M-P, Murray Jl, van Veggel FCJM (2010) Surface modification of upconverting NaYF4 nanoparticles with PEG-phosphate ligands for NIR (800 nm) biolabeling within the biological window. Langmuir ACS J Surf Colloids 26(2):1157-1164

Boyne DA, Savage AM, Griep MH, Beyer FL, Orlicki JA (2017) Process induced alignment of gold nano-rods (GNRs) in thermoplastic polymer composites with tailored optical properties. Polymer 110:250-259

Canizal G, Ascencio JA, Gardea-Torresday J, Yacamán MJ (2001) Multiple twinned gold nanorods grown by bio-reduction techniques. J Nanoparticle Res 3(5):475-481

Cao J, Ma X, Zheng M, Liu J, Ji H (2005) Solvothermal preparation of single-crystalline gold nanorods in novel nonaqueous microemulsions. Chem Lett 34(5):730-731

Cao J, Sun T, Grattan KT (2014) Gold nanorod-based localized surface plasmon resonance biosensors: a review. Sens Actuators B Chem 195:332-35

Chakravarty P, Marches R, Zimmerman NS, Swafford AD-E, Bajaj P, Musselman IH et al (2008) Thermal ablation of tumor cells with antibody-functionalized single-walled carbon nanotubes. Proc Natl Acad Sci U S A 105(25):8697-8702

Chang S-S, Shih C-W, Chen C-D, Lai W-C, Wang CRC (1999) The shape transition of gold nanorods. Langmuir 15(3):701-709 
Chapagain P, Guisbiers G, Kusper M, Geoffrion LD, Benamara M, Golden A, et al. Tuning the Surface Plasmon Resonance of Gold Dumbbell Nanorods. 2021/03/23 ed. ACS Omega. 2021. p. 6871-80.

Chapman BS, Wu W-C, Li Q, Holten-Andersen N, Tracy JB (2017) Heteroaggregation approach for depositing magnetite nanoparticles onto silica-overcoated gold nanorods. Chem Mater 29(24):10362-10368

Chen Y-S, Frey W, Kim S, Homan K, Kruizinga P, Sokolov K et al (2010b) Enhanced thermal stability of silica-coated gold nanorods for photoacoustic imaging and image-guided therapy. Opt Express 18(9):8867-8878

Chen C-L, Kuo L-R, Chang C-L, Hwu Y-K, Huang C-K, Lee S-Y et al (2010a) In situ real-time investigation of cancer cell photothermolysis mediated by excited gold nanorod surface plasmons. Biomaterials 31(14):4104-4112

Chen HM, Peng H-C, Liu R-S, Asakura K, Lee C-L, Lee J-F et al (2005) Controlling the length and shape of gold nanorods. J Phys Chem B 109(42):19553-19555

Chen J, Wang D, Xi J, Au L, Siekkinen A, Warsen A et al (2007) Immuno gold nanocages with tailored optical properties for targeted photothermal destruction of cancer cells. Nano Lett 7(5):1318-1322

Chen H, Zhang X, Dai S, Ma Y, Cui S, Achilefu S, et al. Multifunctional gold nanostar conjugates for tumor imaging and combined photothermal and chemo-therapy. 2013/09/11 ed. Theranostics. 2013. p. 633-49.

Cho YC, Kang JM, Park W, Kim DH, Shin JH, Kim DH, et al. Photothermal therapy via a gold nanoparticle-coated stent for treating stent-induced granulation tissue formation in the rat esophagus. 2021/05/20 ed. Sci Rep. 2021. p. 10558

Choi WI, Kim J-Y, Kang C, Byeon CC, Kim YH, Tae G (2011) Tumor regression in vivo by photothermal therapy based on gold-nanorod-loaded functional nanocarriers. ACS Nano 5(3):1995-2003

Connor EE, Mwamuka J, Gole A, Murphy CJ, Wyatt MD (2005) Gold nanoparticles are taken up by human cells but do not cause acute cytotoxicity. Small Weinh Bergstr Ger 1(3):325-327

Craciun A-M, Suarasan S, Focsan M, Astilean S (2021) One-photon excited photoluminescence of gold nanospheres and its application in prostate specific antigen detection via fluorescence correlation spectroscopy (FCS). Talanta 228:122242

Cui D, Huang P, Zhang C, Ozkan CS, Pan B, Xu P (2011) Dendrimer-modified gold nanorods as efficient controlled gene delivery system under near-infrared light irradiation. J Controlled Release 152:e137-e139

Derfus AM, Chan WCW, Bhatia SN (2004) Probing the cytotoxicity of semiconductor quantum dots. Nano Lett 4(1):11-18

de Oliveira MT, Albrecht W, González-Rubio G, Altantzis T, Hoyos LIP, Béché A et al (2020) 3D Characterization and plasmon mapping of gold nanorods welded by femtosecond laser irradiation. ACS Nano 14(10):12558-12570

Dickerson EB, Dreaden EC, Huang X, El-Sayed IH, Chu H, Pushpanketh S et al (2008) Gold nanorod assisted near-infrared plasmonic photothermal therapy (PPTT) of squamous cell carcinoma in mice. Cancer Lett 269(1):57-66

Ding H, Yong K-T, Roy I, Pudavar HE, Law WC, Bergey EJ et al (2007) Gold nanorods coated with multilayer polyelectrolyte as contrast agents for multimodal imaging. J Phys Chem C 111(34):12552-12557

Du X, Lin W-C, Shou Q, Liang X, Liu H (2019) pH optimization for high-efficiency PEGylation of gold nanorods. Colloid Polym Sci 297(6):891-902

Duan S, Yang Y, Zhang C, Zhao N, Xu F-J (2017) NIR-responsive polycationic gatekeeper-cloaked hetero-nanoparticles for multimodal imaging-guided triple-combination therapy of cancer. Small 13(9):1603133

Durr NJ, Larson T, Smith DK, Korgel BA, Sokolov K, Ben-Yakar A (2007) Two-photon luminescence imaging of cancer cells using molecularly targeted gold nanorods. Nano Lett 7(4):941-945

Eghtedari M, Oraevsky A, Copland JA, Kotov NA, Conjusteau A, Motamedi M (2007) High sensitivity of in vivo detection of gold nanorods using a laser optoacoustic imaging system. Nano Lett 7(7):1914-1918

Elbassal EA, Morris C, Kent TW, Lantz R, Ojha B, Wojcikiewicz EP et al (2017) Gold nanoparticles as a probe for amyloid- $\beta$ oligomer and amyloid formation. J Phys Chem C 121(36):20007-20015

Eustis S, El-Sayed M (2005) Aspect ratio dependence of the enhanced fluorescence intensity of gold nanorods: experimental and simulation study. J Phys Chem B 109(34):16350-16356

Eversole D, Subramanian K, Harrison RK, Bourgeois F, Yuksel A, Ben-Yakar A (2020) Femtosecond Plasmonic Laser Nanosurgery (fs-PLN) mediated by molecularly targeted gold nanospheres at ultra-low pulse fluences. Sci Rep 10(1):12387

Fan Y, Aceta Y, Hessong E, Bengston A, Biageyian LA, Huynh QP et al (2021) Complex resonant scattering behavior in the surface plasmon resonance imaging microscopy of single gold nanorods. J Phys Chem Lett 12(7):2004-2010

Fang S, Lin J, Li C, Huang P, Hou W, Zhang C et al (2017) Dual-stimuli responsive nanotheranostics for multimodal imaging guided trimodal synergistic therapy. Small 13(6):1602580

Farokhnezhad M, Esmaeilzadeh M (2019) Graphene coated gold nanoparticles: an emerging class of nanoagents for photothermal therapy applications. Phys Chem Chem Phys 21(33):18352-18362

Fernando D, Sulthana S, Vasquez Y (2020) Cellular uptake and cytotoxicity of varying aspect ratios of gold nanorods in hela cells. ACS Appl Bio Mater 3(3):1374-1384

Franchini MC, Ponti J, Lemor R, Fournelle M, Broggi F, Locatelli E (2010) Polymeric entrapped thiol-coated gold nanorods: cytotoxicity and suitability as molecular optoacoustic contrast agent. J Mater Chem 20(48):10908-10914

Gao Z, Shao S, Gao W, Tang D, Tang D, Zou S et al (2021) Morphology-invariant metallic nanoparticles with tunable plasmonic properties. ACS Nano 15(2):2428-2438

Gholizadeh N, Pundavela J, Nagarajan R, Dona A, Quadrelli S, Biswas T, et al. Nuclear magnetic resonance spectroscopy of human body fluids and in vivo magnetic resonance spectroscopy: potential role in the diagnosis and management of prostate cancer. 2020/01/16 ed. Urol Oncol. 2020. p. 150-73.

Gollub MJ, Blazic I, Felder S, Knezevic A, Gonen M, Garcia-Aguilar J et al (2019) Value of adding dynamic contrastenhanced MRI visual assessment to conventional MRI and clinical assessment in the diagnosis of complete tumour response to chemoradiotherapy for rectal cancer. Eur Radiol 29(3):1104-1113

Großmann R, Aranson IS, Peruani F (2020) A particle-field approach bridges phase separation and collective motion in active matter. Nat Commun 11(1):5365

Han HS, Choi KY (2021) Advances in nanomaterial-mediated photothermal cancer therapies: toward clinical applications. Biomedicines. 9(3):305no

Harper-Harris J, Kant K, Singh G (2021) Oleic acid-assisted synthesis of tunable high-aspect-ratio multiply-twinned gold nanorods for bioimaging. ACS Appl Nano Mater 4(4):3325-3330 
Harris-Birtill D, Singh M, Zhou Y, Shah A, Ruenraroengsak P, Gallina ME et al (2017) Gold nanorod reshaping in vitro and in vivo using a continuous wave laser. PLoS ONE 12(10):e0185990

Hartland GV (2006) Coherent excitation of vibrational modes in metallic nanoparticles. Annu Rev Phys Chem 57:403-430 Hashemi F, Hormozi-Nezhad MR, Corbo C, Farvadi F, Shokrgozar MA, Mehrjoo M et al (2019) Laser irradiation affects the biological identity and cellular uptake of plasmonic nanoparticles. Nanoscale 11(13):5974-5981

Hu KW, Huang CC, Hwu JR, Su WC, Shieh DB, Yeh CS (2008) A new photothermal therapeutic agent: core-free nanostructured Au x Ag 1-x dendrites. Chemistry 14(10):2956-2964

Huang L, Ao L, Hu D, Wang W, Sheng Z, Su W (2016) Magneto-plasmonic nanocapsules for multimodal-imaging and magnetically guided combination cancer therapy. Chem Mater 28(16):5896-5904

Huang P, Bao L, Zhang C, Lin J, Luo T, Yang D et al (2011) Folic acid-conjugated silica-modified gold nanorods for X-ray/CT imaging-guided dual-mode radiation and photo-thermal therapy. Biomaterials 32(36):9796-9809

Huang X, El-Sayed IH, Qian W, El-Sayed MA (2006) Cancer cell imaging and photothermal therapy in the near-infrared region by using gold nanorods. J Am Chem Soc 128(6):2115-2120

Huang X, El-Sayed IH, Qian W, El-Sayed MA (2007) Cancer cells assemble and align gold nanorods conjugated to antibodies to produce highly enhanced, sharp, and polarized surface Raman spectra: a potential cancer diagnostic marker. Nano Lett 7(6):1591-1597

Huang X, Jain PK, El-Sayed IH, El-Sayed MA (2008) Plasmonic photothermal therapy (PPTT) using gold nanoparticles. Lasers Med Sci 23(3):217-228

Huang W, Qian W, Jain PK, El-Sayed MA (2007) The effect of plasmon field on the coherent lattice phonon oscillation in electron-beam fabricated gold nanoparticle pairs. Nano Lett 7(10):3227-3234

Huang H-C, Rege K, Heys JJ (2010) Spatiotemporal temperature distribution and cancer cell death in response to extracellular hyperthermia induced by gold nanorods. ACS Nano 4(5):2892-2900

Huff TB, Tong L, Zhao Y, Hansen MN, Cheng J-X, Wei A. Hyperthermic effects of gold nanorods on tumor cells. 2007;

lqbal M, Chung Y-I, Tae G (2007) An enhanced synthesis of gold nanorods by the addition of Pluronic (F-127) via a seed mediated growth process. J Mater Chem 17(4):335-342

Jain PK, Lee KS, El-Sayed IH, El-Sayed MA (2006) Calculated absorption and scattering properties of gold nanoparticles of different size, shape, and composition: applications in biological imaging and biomedicine. J Phys Chem B 110(14):7238-7248

Jana NR (2003) Nanorod shape separation using surfactant assisted self-assembly. Chem Commun 15:1950-1951

Jana NR (2005) Gram-scale synthesis of soluble, near-monodisperse gold nanorods and other anisotropic nanoparticles. Small Weinh Bergstr Ger 1(8-9):875-882

Jana NR, Gearheart L, Murphy CJ (2001) Wet chemical synthesis of high aspect ratio cylindrical gold nanorods. J Phys Chem B 105(19):4065-4067

Jana NR, Gearheart L, Murphy CJ (2001) Seed-mediated growth approach for shape-controlled synthesis of spheroidal and rod-like gold nanoparticles using a surfactant template. Adv Mater 13(18):1389-1393

Jana NR, Gearheart LA, Obare SO, Johnson CJ, Edler KJ, Mann S et al (2002) Liquid crystalline assemblies of ordered gold nanorods. J Mater Chem 12(10):2909-2912

Jeevanandam J, Balu SK, Andra S, Danquah MK, Vidyavathi M, Muthalagu M. Quantum Dots Synthesis and Application. In: Mubarak NM, Khalid M, Walvekar R, Numan A, editors. Contemp. Nanomater. Mater. Eng. Appl. Cham: Springer International Publishing; 2021 (cited 2021 Mar 31). p. 229-65. https://doi.org/10.1007/978-3-030-62761-4_9

Jelveh S, Chithrani DB (2011) Gold nanostructures as a platform for combinational therapy in future cancer therapeutics. Cancersr 3(1):1081-1110

Jiang Y, Guo Z, Fang J, Wang B, Lin Z, Chen Z-S et al (2020) A multi-functionalized nanocomposite constructed by gold nanorod core with triple-layer coating to combat multidrug resistant colorectal cancer. Mater Sci Eng C 107:110224

Kawamura G, Yang Y, Nogami M (2007) Facile assembling of gold nanorods with large aspect ratio and their surfaceenhanced Raman scattering properties. Appl Phys Lett 90(26):261908

Khanal BP, Zubarev ER (2019) Chemical transformation of nanorods to nanowires: reversible growth and dissolution of anisotropic gold nanostructures. ACS Nano 13(2):2370-2378

Khlebtsov N, Bogatyrev V, Dykman L, Khlebtsov B, Staroverov S, Shirokov A, et al. Analytical and theranostic applications of gold nanoparticles and multifunctional nanocomposites. 2013/03/09 ed. Theranostics. 2013. p. 167-80.

Kim Y-J, Cho G, Song JH (2006) Synthesis of size and shape-selective Au nanocrystals via proton beam irradiation. Nucl Instrum Methods Phys Res Sect B Beam Interact Mater at 246(2):351-354

Kim K, Huang S-W, Ashkenazi S, O'Donnell M, Agarwal A, Kotov NA et al (2007) Photoacoustic imaging of early inflammatory response using gold nanorods. Appl Phys Lett 90(22):223901

Kim J, Park S, Lee JE, Jin SM, Lee JH, Lee IS et al (2006) Designed fabrication of multifunctional magnetic gold nanoshells and their application to magnetic resonance imaging and photothermal therapy. Angew Chem Int Ed Engl 45(46):7754-7758

Kim F, Song JH, Yang P (2002) Photochemical synthesis of gold nanorods. J Am Chem Soc 124(48):14316-14317

Kim YS, Han IH, Lee IS, Lee JS, Choi BK. Imaging findings of solitary spinal bony lesions and the differential diagnosis of benign and malignant lesions. J Korean Neurosurg Soc. 2012/10/24 ed. 2012;52(2):126-32.

Kim HJ, Wang W, Bu W, Hossen MM, Londoño-Calderon A, Hillier AC, et al. Salt Mediated Self-Assembly of Poly(ethylene glycol)-Functionalized Gold Nanorods. 2020/01/01 ed. Sci Rep. 2019. p. 20349

Kwon Y, Choi Y, Jang J, Yoon S, Choi J (2020) NIR laser-responsive PNIPAM and gold nanorod composites for the engineering of thermally reactive drug delivery nanomedicine. Pharmaceutics 12(3):204

Lee K-S, El-Sayed MA (2005) Dependence of the enhanced optical scattering efficiency relative to that of absorption for gold metal nanorods on aspect ratio, size, end-cap shape, and medium refractive index. J Phys Chem B 109(43):20331-20338

Leonov AP, Zheng J, Clogston JD, Stern ST, Patri AK, Wei A. Detoxification of gold nanorods by treatment with polystyrenesulfonate. ACS Nano. 2009/02/12 ed. 2008;2(12):2481-8. 
Leontidis E, Kleitou K, Kyprianidou-Leodidou T, Bekiari V, Lianos P (2002) Gold colloids from cationic surfactant solutions. 1. Mechanisms that control particle morphology. Langmuir 18(9):3659-3668

Li JL, Day D, Gu M (2008) Ultra-low energy threshold for cancer photothermal therapy using transferrin-conjugated gold nanorods. Adv Mater 20(20):3866-3871

Li C, Feng K, Xie N, Zhao W, Ye L, Chen B et al (2020) Mesoporous silica-coated gold nanorods with designable anchor peptides for chemo-photothermal cancer therapy. ACS Appl Nano Mater 3(6):5070-5078

Li Z, Huang P, Zhang X, Lin J, Yang S, Liu B et al (2010) RGD-conjugated dendrimer-modified gold nanorods for in vivo tumor targeting and photothermal therapy. Mol Pharm 7(1):94-104

Li Y, Lu W, Huang Q, Huang M, Li C, Chen W (2010) Copper sulfide nanoparticles for photothermal ablation of tumor cells. Nanomed 5(8):1161-1171

Li P-C, Wang CR-C, Shieh D-B, Wei C-W, Liao C-K, Poe C et al (2008) In vivo photoacoustic molecular imaging with simultaneous multiple selective targeting using antibody-conjugated gold nanorods. Opt Express 16(23):18605-18615

Li F, Wang K, Tan Z, Guo C, Liu Y, Tan H et al (2020) Solvent quality-mediated regioselective modification of gold nanorods with thiol-terminated polymers. Langmuir 36(49):15162-15168

Lien HNT, Phan AD, Van Khanh BT, Thuy NT, Nghia TN, Nhung MHT et al (2020) Applications of mesoporous silica-encapsulated gold nanorods loaded doxorubicin in chemo-photothermal therapy. ACS Omega 5(32):20231-20237

Link S, Burda C, Nikoobakht B, El-Sayed MA (1999) How long does it take to melt a gold nanorod?: A femtosecond pump-probe absorption spectroscopic study. Chem Phys Lett 315(1):12-18

Link S, El-Sayed MA (2001) Spectroscopic determination of the melting energy of a gold nanorod. J Chem Phys 114(5):2362-2368

Link S, Wang ZL, El-Sayed MA (2000) How does a gold nanorod melt? J Phys Chem B 104(33):7867-7870

Liu M, Guyot-Sionnest P (2004) Synthesis and optical characterization of Au/Ag Core/Shell nanorods. J Phys Chem B 108(19):5882-5888

Liu M, Guyot-Sionnest P (2006) Preparation and optical properties of silver chalcogenide coated gold nanorods. J Mater Chem 16(40):3942-3945

Liu R, Ye X, Cui T. Recent Progress of Biomarker Detection Sensors. 2020/10/31 ed. Res. Wash C. 2020. p. 7949037

Longoni M, Zalaffi MS, de Ferri L, Stortini AM, Pojana G, Ugo P. Surface Enhanced Raman Spectroscopy With Electrodeposited Copper Ultramicro-Wires With/Without Silver Nanostars Decoration. Nanomater. Basel. 2021/03/07 ed. 2021;11(2)

Lu S, Wu Z, Jayaraman A (2021) Molecular modeling and simulation of polymer nanocomposites with nanorod fillers. J Phys Chem B 125(9):2435-2449

Lu W, Xiong C, Zhang G, Huang Q, Zhang R, Zhang JZ et al (2009) Targeted photothermal ablation of murine melanomas with melanocyte-stimulating hormone analog-conjugated hollow gold nanospheres. Clin Cancer Res off J. 15(3):876-886

Luo G-F, Chen W-H, Lei Q, Qiu W-X, Liu Y-X, Cheng Y-J et al (2016) A triple-collaborative strategy for high-performance tumor therapy by multifunctional mesoporous silica-coated gold nanorods. Adv Funct Mater 26(24):4339-4350

Luo T, Huang P, Gao G, Shen G, Fu S, Cui D et al (2011) Mesoporous silica-coated gold nanorods with embedded indocyanine green for dual mode X-ray CT and NIR fluorescence imaging. Opt Express 19(18):17030-17039

Lv Z, He S, Wang Y, Zhu X. Noble Metal Nanomaterials for NIR-Triggered Photothermal Therapy in Cancer. 2021/01/21 ed. Adv Heal. Mater. 2021. p. e2001806

Mansour Y, Battie Y, Naciri AE, Chaoui N (2019) Mechanisms and advanced photothermal modelling of laser-induced shape transformations of colloidal gold nanorods by nanosecond laser pulses. Nanoscale 11(24):11679-11686

Mantri Y, Jokerst JV. Engineering Plasmonic Nanoparticles for Enhanced Photoacoustic Imaging. ACS Nano. 2020/08/19 ed. 2020;14(8):9408-22.

Marangoni VS, Cancino-Bernardi J, Zucolotto V (2016) Synthesis, physico-chemical properties, and biomedical applications of gold nanorods - a review. J Biomed Nanotechnol 12(6):1136-1158

Martin CR (1996) Membrane-based synthesis of nanomaterials. Chem Mater 8(8):1739-1746

Mb B, Manippady SR, Saxena M, John NS, Balakrishna RG et al (2020) Gold Nanorods as an efficient substrate for the detection and degradation of pesticides. Langmuir 36(26):7332-7344

Meng L, Li H, Zhao W, Li Z, Lin C (2020) Preparation and plasmon resonance properties of Au nanorods and Au nanorods@SiO 2. Gold Bull 53(1):31-37

Millstone JE, Wei W, Jones MR, Yoo H, Mirkin CA (2008) lodide ions control seed-mediated growth of anisotropic gold nanoparticles. Nano Lett 8(8):2526-2529

Miranda OR, Ahmadi TS (2005) Effects of intensity and energy of CW UV light on the growth of gold nanorods. J Phys Chem B 109(33):15724-15734

Mohamed MB, Ismail KZ, Link S, El-Sayed MA (1998) Thermal reshaping of gold nanorods in micelles. J Phys Chem B 102(47):9370-9374

Morales-Dalmau J, Vilches C, de Miguel I, Sanz V, Quidant R (2018) Optimum morphology of gold nanorods for lightinduced hyperthermia. Nanoscale 10(5):2632-2638

Mori M, Akashi-Tanaka S, Suzuki S, Daniels MI, Watanabe C, Hirose M, et al. Diagnostic accuracy of contrast-enhanced spectral mammography in comparison to conventional full-field digital mammography in a population of women with dense breasts. 2016/03/05 ed. Breast Cancer. 2017. p. 104-10

Murphy CJ, Sau TK, Gole AM, Orendorff CJ, Gao J, Gou L et al (2005) Anisotropic metal nanoparticles:synthesis, assembly, and optical applications. J Phys Chem B 109(29):13857-13870

Naseer UK, Zahir M, Liu XK, Lin J, Zheng QH, Zhang HJ, et al. Ultrasensitive detection of exosome using biofunctionalized gold nanorods on a silver-island film. Nano Lett; 2021. https://doi.org/10.1021/acs.nanolett.1c00830.

Nikoobakht B, El-Sayed MA (2003) Preparation and growth mechanism of gold nanorods (NRs) using seed-mediated growth method. Chem Mater 15(10):1957-1962

Noh Y, Kim M-J, Mun H, Jo E-J, Lee H, Kim M-G (2019) Aptamer-based selective KB cell killing by the photothermal effect of gold nanorods. J Nanoparticle Res 21(6):1-10 
Oldenburg AL, Hansen MN, Ralston TS, Wei A, Boppart SA (2009) Imaging gold nanorods in excised human breast carcinoma by spectroscopic optical coherence tomography. J Mater Chem 19(35):6407-6411

Onsager L (1949) The effects of shape on the interaction of colloidal particles. Ann NY Acad Sci 51(4):627-659

Ortiz-Castillo JE, Gallo-Villanueva RC, Madou MJ, Perez-Gonzalez VH (2020) Anisotropic gold nanoparticles: a survey of recent synthetic methodologies. Coord Chem Rev 425:213489

Parchur AK, Sharma G, Jagtap JM, Gogineni VR, LaViolette PS, Flister MJ et al (2018) Vascular interventional radiologyguided photothermal therapy of colorectal cancer liver metastasis with theranostic gold nanorods. ACS Nano 12(7):6597-6611

Park SI, Song H-M (2021) Several shapes of single crystalline gold nanomaterials prepared in the surfactant mixture of CTAB and pluronics. ACS Omega 6(5):3625-3636

Parviainen H, Lumme K (2008) Scattering from rough thin films: DDA-simulations. J Opt Soc Am A 25(1):90

Peng J, Qi T, Liao J, Chu B, Yang Q, Qu Y, et al. Mesoporous magnetic gold "nanoclusters" as theranostic carrier for chemophotothermal co-therapy of breast cancer. 2014/06/03 ed. Theranostics. 2014. p. 678-92

Perera T, Gunapala SD, Stockman MI, Premaratne M. Plasmonic properties of metallic nanoshells in the quantum limit: from single particle excitations to plasmons. J Phys Chem C. 2020

Peters SME, Verheijen MA, Prins MWJ, Zijlstra P (2015) Strong reduction of spectral heterogeneity in gold bipyramids for single-particle and single-molecule plasmon sensing. Nanotechnology 27(2):024001

Picca DF, Gutiérrez MV, Bragas AV, Scarpettini AF (2018) Monitoring the photothermal reshaping of individual plasmonic nanorods with coherent mechanical oscillations. J Phys Chem C 122(51):29598-29606

Pissuwan D, Valenzuela SM, Cortie MB (2008) Prospects for gold nanorod particles in diagnostic and therapeutic applications. Biotechnol Genet Eng Rev 25(1):93-112

Pissuwan D, Valenzuela SM, Killingsworth MC, Xu X, Cortie MB (2007) Targeted destruction of murine macrophage cells with bioconjugated gold nanorods. J Nanoparticle Res 9(6):1109-1124

Prasad BR, Nikolskaya N, Connolly D, Smith TJ, Byrne SJ, Gérard VA et al (2010) Long-term exposure of CdTe quantum dots on PC12 cellular activity and the determination of optimum non-toxic concentrations for biological use. J Nanobiotechnology 8:7

Qazi UY, Javaid R (2016) A review on metal nanostructures: preparation methods and their potential applications. Adv Nanoparticles. 5(1):27-43

Qin J, Peng Z, Li B, Ye K, Zhang Y, Yuan F et al (2015) Gold nanorods as a theranostic platform for in vitro and in vivo imaging and photothermal therapy of inflammatory macrophages. Nanoscale 7(33):13991-14001

Qiu W-X, Liu L-H, Li S-Y, Lei Q, Luo G-F, Zhang X-Z (2017) ACPI conjugated gold nanorods as nanoplatform for dual image guided activatable photodynamic and photothermal combined therapy in vivo. Small 13(18):1603956

Ramasamy M, Lee SS, Yi DK, Kim K (2014) Magnetic, optical gold nanorods for recyclable photothermal ablation of bacteria. J Mater Chem B 2(8):981-988

Ratto F, Centi S, Avigo C, Borri C, Tatini F, Cavigli L et al (2016) A robust design for cellular vehicles of gold nanorods for multimodal imaging. Adv Funct Mater 26(39):7178-7185

Razek AA, Talaat M, El-Serougy L, Gaballa G, Abdelsalam M (2019) Clinical applications of arterial spin labeling in brain tumors. J Comput Assist Tomogr 43(4):525-532

Razek AA, Castillo M. Imaging appearance of primary bony tumors and pseudo-tumors of the spine. J Neuroradiol. 2009/09/29 ed. 2010;37(1):37-50

Razek AA, Fathy A, Gawad TA. Correlation of apparent diffusion coefficient value with prognostic parameters of lung cancer. 2011/03/18 ed. J Comput Assist Tomogr. 2011. p. 248-52

Robinson JT, Tabakman SM, Liang Y, Wang H, Sanchez Casalongue H, Vinh D et al (2011) Ultrasmall reduced graphene oxide with high near-infrared absorbance for photothermal therapy. J Am Chem Soc 133(17):6825-6831

Roy D, Xu Y, Rajendra R, Wu L, Bai P, Ballav N (2020) Gold nanoearbuds: seed-mediated synthesis and the emergence of three plasmonic peaks. J Phys Chem Lett 11(9):3211-3217

Rusling JF. Multiplexed electrochemical protein detection and translation to personalized cancer diagnostics. Anal Chem. 2013/05/03 ed. 2013;85(11):5304-10

Sen GT, Ozkemahli G, Shahbazi R, Erkekoglu P, Ulubayram K, Kocer-Gumusel B (2020) The effects of polymer coating of gold nanoparticles on oxidative stress and DNA damage. Int J Toxicol 39(4):328-340

Sethi A, Rafiee M, Chandra S, Ahmed H, McCormack S (2019) Unified methodology for fabrication and quantification of gold nanorods, gold core silver shell nanocuboids, and their polymer nanocomposites. Langmuir 35(40):13011-13019

Shilpi S, Khatri K (2015) Gold nanoparticles as carrier(s) for drug targeting and imaging. Pharm Nanotechnol 3(3):154-170

Smith DK, Korgel BA (2008) The importance of the CTAB surfactant on the colloidal seed-mediated synthesis of gold nanorods. Langmuir 24(3):644-649

Smith RA, Brooks D, Cokkinides V, Saslow D, Brawley OW. Cancer screening in the United States, 2013: a review of current American Cancer Society guidelines, current issues in cancer screening, and new guidance on cervical cancer screening and lung cancer screening. 2013/02/05 ed. CA Cancer J Clin. 2013. p. 88-105

Song J, Yang X, Jacobson O, Huang P, Sun X, Lin L, et al. Ultrasmall Gold Nanorod Vesicles with Enhanced Tumor Accumulation and Fast Excretion from the Body for Cancer Therapy. 2015/07/23 ed. Adv Mater. 2015. p. 4910-7

Sumer Z, Striolo A (2020) Nanoparticles shape-specific emergent behaviour on liquid crystal droplets. Mol Syst Des Eng. 5(2):449-460

Sun H, Yuan Q, Zhang B, Ai K, Zhang P, Lu L (2011) Gdlll functionalized gold nanorods for multimodal imaging applications. Nanoscale 3(5):1990-1996

Takahashi H, Niidome Y, Niidome T, Kaneko K, Kawasaki H, Yamada S (2006) Modification of gold nanorods using phosphatidylcholine to reduce cytotoxicity. Langmuir 22(1):2-5

Thirkill H. Ultramicroscopy and ultramicroscopic particles Sci Prog Twent Century 1906-1916. Science Reviews 2000 Ltd.; 1909:4(13):55-89.

Tong L, Zhao Y, Huff TB, Hansen MN, Wei A, Cheng J-X (2007) Gold nanorods mediate tumor cell death by compromising membrane integrity. Adv Mater 19:3136-3141 
Torres-Vanegas JD, Cruz JC, Reyes LH. Delivery Systems for Nucleic Acids and Proteins: Barriers, Cell Capture Pathways and Nanocarriers. Pharmaceutics. 2021/04/04 ed. 2021;13(3).

Truong PL, Cao C, Park S, Kim M, Sim SJ (2011) A new method for non-labeling attomolar detection of diseases based on an individual gold nanorod immunosensor. Lab Chip 11(15):2591-2597

Villar-Alvarez E, Cambón A, Pardo A, Mosquera VX, Bouzas-Mosquera A, Topete A et al (2018) Gold nanorod-based nanohybrids for combinatorial therapeutics. ACS Omega 3(10):12633-12647

von Maltzahn G, Park J-H, Agrawal A, Bandaru NK, Das SK, Sailor MJ et al (2009) Computationally guided photothermal tumor therapy using long-circulating gold nanorod antennas. Cancer Res 69(9):3892-3900

Wang C-U, Arai Y, Kim I, Jang W, Lee S, Hafner JH et al (2012) Surface-modified gold nanorods for specific cell targeting. J Korean Phys Soc 60(10):1700-1707

Wang H, Huff TB, Zweifel DA, He W, Low PS, Wei A et al (2005) In vitro and in vivo two-photon luminescence imaging of single gold nanorods. Proc Natl Acad Sci 102(44):15752-15756

Wang Y, Wang F, Guo Y, Chen R, Shen Y, Guo A et al (2014) Controlled synthesis of monodisperse gold nanorods with different aspect ratios in the presence of aromatic additives. J Nanoparticle Res 16(12):1-11

Wang C, Wang T, Ma Z, Su Z (2005) pH-tuned synthesis of gold nanostructures from gold nanorods with different aspect ratios. Nanotechnology 16(11):2555-2560

Wei A, Leonov AP, Wei Q (2010) Gold nanorods: multifunctional agents for cancer imaging and therapy. Methods Mol Biol Clifton NJ 624:119-130

Weissleder R (2001) A clearer vision for in vivo imaging. Nat Biotechnol 19(4):316-317

Wiesner J, Wokaun A (1989) Anisometric gold colloids. Preparation, characterization, and optical properties. Chem Phys Lett 157(6):569-575

Wijaya A, Hamad-Schifferli K (2008) Ligand customization and DNA functionalization of gold nanorods via round-trip phase transfer ligand exchange. Langmuir 24(18):9966-9969

Wong BS, Yoong SL, Jagusiak A, PanczykT, Ho HK, Ang WH, et al. Carbon nanotubes for delivery of small molecule drugs. 2013/08/21 ed. Adv Drug Deliv Rev. 2013. p. 1964-2015.

Wongkaew N, Simsek M, Griesche C, Baeumner AJ (2019) Functional nanomaterials and nanostructures enhancing electrochemical biosensors and lab-on-a-chip performances: recent progress, applications, and future perspective. Chem Rev 119(1):120-194

Wu H-Y, Chu H-C, Kuo T-J, Kuo C-L, Huang MH (2005) Seed-mediated synthesis of high aspect ratio gold nanorods with nitric acid. Chem Mater 17(25):6447-6451

Xu H, Ohulchanskyy TY, Yakovliev A, Zinyuk R, Song J, Liu L et al (2019) Nanoliposomes co-encapsulating CT imaging contrast agent and photosensitizer for enhanced, imaging guided photodynamic therapy of cancer. Theranostics 9(5):1323-1335

Xu Z-C, Shen C-M, Xiao C-W, Yang T-Z, Chen S-T, Li H-L et al (2006) Fabrication of gold nanorod self-assemblies from rod and sphere mixtures via shape self-selective behavior. Chem Phys Lett 432(1):222-225

Yang D-P, Cui D-X (2008) Advances and prospects of gold nanorods. Chem Asian J 3(12):2010-2022

Yaseen M, Humayun M, Khan A, Usman M, Ullah H, Tahir AA et al (2021) Preparation, functionalization, modification, and applications of nanostructured gold: a critical review. Energies 14(5):1278

Younis MR, An RB, Yin Y-C, Wang S, Ye D, Xia X-H (2019) Plasmonic nanohybrid with high photothermal conversion efficiency for simultaneously effective antibacterial/anticancer photothermal therapy. ACS Appl Bio Mater 2(9):3942-3953

Yu YY, Chang S-S, Lee C-L, Wang CRC (1997) Gold nanorods: electrochemical synthesis and optical properties. J Phys Chem B 101(34):6661-6664

Yu C, Varghese L, Irudayaraj J (2007) Surface modification of cetyltrimethylammonium bromide-capped gold nanorods to make molecular probes. Langmuir 23(17):9114-9119

Zhan C, Huang Y, Lin G, Huang S, Zeng F, Wu S. A gold nanocage/cluster hybrid structure for whole-body multispectral optoacoustic tomography imaging, egfr inhibitor delivery, and photothermal therapy. 2019/06/28 ed. Small. 2019. p. e1900309

Zhang JZ (2010) Biomedical applications of shape-controlled plasmonic nanostructures: a case study of hollow gold nanospheres for photothermal ablation therapy of cancer. J Phys Chem Lett 1 (4):686-695

Zhang L, Su H, Cai J, Cheng D, Ma Y, Zhang J et al (2016) A multifunctional platform for tumor angiogenesis-targeted chemo-thermal therapy using polydopamine-coated gold nanorods. ACS Nano 10(11):10404-10417

Zhang Y-F, Wang J-H, Ma L, Nan F, Cheng Z-Q, Zhou L et al (2015) Growth of silver-coated gold nanoshells with enhanced linear and nonlinear optical responses. J Nanoparticle Res 17(3):1-10

Zhang Z, Wang L, Wang J, Jiang X, Li X, Hu Z et al (2012) Theranostics: mesoporous silica-coated gold nanorods as a lightmediated multifunctional theranostic platform for cancer treatment. Adv Mater 24(11):1349-1349

Zhao X, Yang C-X, Chen L-G, Yan X-P (2017) Dual-stimuli responsive and reversibly activatable theranostic nanoprobe for precision tumor-targeting and fluorescence-guided photothermal therapy. Nat Commun 8(1):14998

Zharov VP, Galitovskaya EN, Johnson C, Kelly T (2005) Synergistic enhancement of selective nanophotothermolysis with gold nanoclusters: potential for cancer therapy. Lasers Surg Med 37(3):219-226

Zhu Y-J, Hu X-L (2003) Microwave-polyol preparation of single-crystalline gold nanorods and nanowires. Chem Lett 32(12):1140-1141

Zijlstra P, Bullen C, Chon JWM, Gu M (2006) High-temperature seedless synthesis of gold nanorods. J Phys Chem B 110(39):19315-19318

Zweifel DA, Wei A (2005) Sulfide-arrested growth of gold nanorods. Chem Mater 17(16):4256-4261

\section{Publisher's Note}

Springer Nature remains neutral with regard to jurisdictional claims in published maps and institutional affiliations. 